\title{
Design, deployment, and status of borehole observatory systems used for single-hole and cross-hole experiments, IODP Expedition 327, eastern flank of Juan de Fuca Ridge ${ }^{1}$
}

A.T. Fisher, ${ }^{2}$ C.G. Wheat, ${ }^{2}$ K. Becker, ${ }^{2}$ J. Cowen, ${ }^{2}$ B. Orcutt, ${ }^{2}$ S. Hulme, ${ }^{2}$ K. Inderbitzen, ${ }^{2}$ A. Haddad, ${ }^{2}$ T.L. Pettigrew, ${ }^{3}$ E.E. Davis, ${ }^{4}$ H. Jannasch, ${ }^{5}$ K. Grigar, ${ }^{6}$ R. Aduddell, ${ }^{6}$ R. Meldrum, ${ }^{4}$

R. Macdonald, ${ }^{4}$ and K.J. Edwards ${ }^{7}$

\section{Chapter contents}

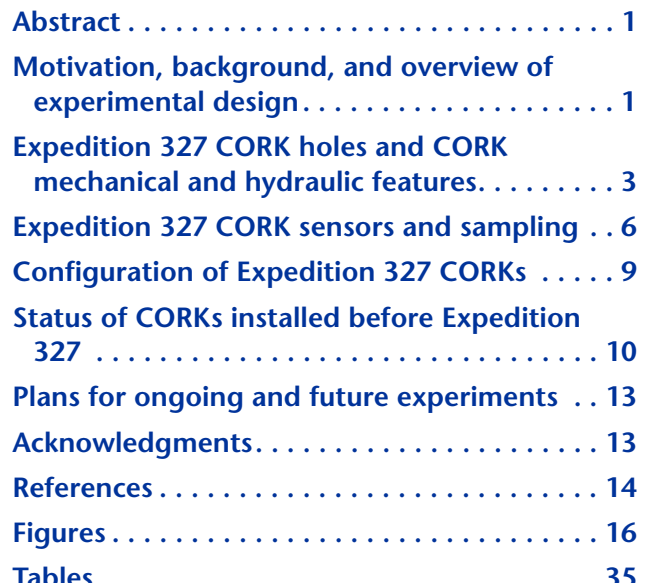

${ }^{1}$ Fisher, A.T., Wheat, C.G., Becker, K., Cowen, J., Orcutt, B., Hulme, S., Inderbitzen, K., Haddad, A., Pettigrew, T.L., Davis, E.E., Jannasch, H., Grigar, K., Aduddell, R., Meldrum, R., Macdonald, R., and Edwards, K.J., 2011. Design, deployment, and status of borehole observatory systems used for single-hole and cross-hole experiments, IODP Expedition 327, eastern flank of Juan de Fuca Ridge. In Fisher, A.T., Tsuji, T., Petronotis, K., and the Expedition 327 Scientists, Proc. IODP, 327: Tokyo (Integrated Ocean Drilling Program Management International, Inc.). doi:10.2204/iodp.proc.327.107.2011

${ }^{2}$ Expedition 327 Scientists' addresses. ${ }^{3}$ Mohr Engineering Division, Stress Engineering Services, Houston TX 77041, USA.

${ }^{4}$ Pacific Geoscience Centre, Geological Survey of Canada, Sidney BC V8L 4B2, Canada.

${ }^{5}$ Monterey Bay Aquarium Research Institute, Moss Landing CA 95039, USA.

${ }^{6}$ Integrated Ocean Drilling Program, Texas A\&M University, College Station TX 77845, USA.

${ }^{7}$ Department of Earth Sciences and Department of Biological Sciences, University of Southern California, Los Angeles CA 90089, USA.

\section{Abstract}

Integrated Ocean Drilling Program (IODP) Expedition 327 installed two new subseafloor borehole observatory systems ("CORKs") in 3.5 m.y. old upper ocean crust on the eastern flank of Juan de Fuca Ridge in Holes U1362A and U1362B. Expedition 327 participants also recovered part of an instrument string previously deployed in a CORK in Hole U1301B and deployed a short replacement string. These observatories are part of a network of six CORKs that was designed to monitor, sample, and complete multidisciplinary cross-hole experiments. We present an overview of project goals and describe the design, construction, and deployment of new CORK systems. We also provide an update on the status of preexisting CORK systems as of the start of Expedition 327. Additional CORK servicing and sampling are scheduled for summer 2011 and 2012, including a long-term free-flow perturbation experiment that will test the large-scale directional properties of the upper ocean crust around the observatories.

\section{Motivation, background, and overview of experimental design}

\section{Long-term borehole observatory systems}

Subseafloor borehole observatory systems ("CORKs") are designed to (1) seal one or more depth intervals of a borehole so that thermal, pressure, chemical, and microbiological conditions can equilibrate following the dissipation of drilling and other operational disturbances; (2) facilitate collection of fluid and microbiological samples and temperature and pressure data using autonomous samplers and data logging systems; and (3) serve as longterm monitoring points for large-scale crustal testing, including formation response to perturbation experiments (Becker and Davis, 2005; Davis et al., 1992a; Wheat et al.). The development of CORK systems was motivated by the desire to address a broad range of scientific objectives that have been the focus of scientific ocean drilling for decades, particularly those associated with submarine hydrogeology, lithospheric and hydrothermal fluid evolu- 
tion, tectonic processes and geohazards, and the nature of the deep microbial biosphere. In many cases, CORKs provide the only available technology for collecting data and samples that are essential for developing a process-based understanding of these subseafloor systems.

The CORKs developed for Integrated Ocean Drilling Program (IODP) Expedition 327 share features with systems deployed during earlier drilling expeditions, particularly Ocean Drilling Program (ODP) Leg 205 and IODP Expedition 301. However, substantial modifications were made to the Expedition 327 CORK designs on the basis of specific technical and scientific goals of planned experiments and on experience gained since Expedition 301. In this paper, we describe the design and deployment of two new CORK systems during Expedition 327. We also provide a status update on CORK systems deployed during ODP Leg 168 and IODP Expedition 301, reporting on how they were configured as of the start of Expedition 327. Finally, we describe plans for using these systems over the next several years during a series of multidisciplinary experiments. We begin with a brief overview of the motivation for Expedition 327 and related (earlier) drilling and nondrilling expeditions and experiments.

\section{ODP Leg 168 and IODP Expeditions 301 and 327 and related experiments}

During ODP Leg 168 a transect of eight sites was drilled across 0.9-3.6 m.y. old seafloor east of Juan de Fuca Ridge to collect sediment, rock, and fluid samples; determine thermal, geochemical, and hydrogeologic conditions in basement; and install four CORK observatories in the upper crust (Davis, Fisher, Firth, et al., 1997). Two of these CORKs were placed in 3.5-3.6 m.y. old volcanic oceanic crust near the eastern end of the drilling transect in Holes 1026B and 1027C (Fig. F1). Expedition 301 returned to this area, drilled deeper into basement at Site U1301 (Fig. F1), and conducted single-hole experiments; sampled sediment, basalt, and microbiological materials; replaced the observatory in Hole 1026B; and established two multilevel observatories in Holes U1301A and U1301B for use in long-term cross-hole experiments (Fisher et al., 2005). The primary goals of Expedition 327 were to (1) drill two new basement holes at Site U1362 (Fig. F1), core and wireline log one of these holes across a depth range of 100-360 meters subbasement (msb), conduct a $24 \mathrm{~h}$ pumping test, initiate a tracer-injection experiment, and install multilevel CORKs; (2) recover the existing CORK installed in Hole 1027C, deepen the hole by $40 \mathrm{~m}$, and install a new multilevel CORK with instrumentation; and (3) recover and replace the instru- ment string deployed in the CORK in Hole U1301B. Work in Hole 1027C could not be completed during Expedition 327, but other primary and secondary objectives were achieved (see the "Expedition 327 summary" chapter).

Considerable time and resources were applied between Expeditions 301 and 327 to service the CORK observatories in Holes 1026B, 1027C, U1301A, and U1301B. The samplers and loggers deployed in the Expedition 301 CORKs had operational life spans of 4-6 y; all of the seafloor and subseafloor instruments originally installed in these systems had to be replaced prior to the start of Expedition 327 so that these systems could be used to monitor single- and cross-hole response for several years following drillship operations. In addition, the CORKs installed in Holes U1301A and U1301B during Expedition 301 were not sealed as intended (Fisher et al., 2005), and data and samples collected during subsequent remotely operated vehicle (ROV) and submersible servicing operations showed that both observatory systems were leaking (Davis et al., 2010; Fisher et al., 2008). Several attempts were made to seal these systems using cement delivered initially with a submersible, and eventually with the R/V JOIDES Resolution during IODP Expedition 321T (Fisher and IODP Expedition 321T Scientific Party, 2010).

\section{Experimental borehole configurations}

During Leg 168, Hole 1026B was drilled to 295 meters below seafloor (mbsf), cased across the sediment/basement interface, and extended to $48 \mathrm{msb}$ (Shipboard Scientific Party, 1997). Upper basement was unstable in this location, and it was necessary to deploy an old piece of drill pipe as a liner across uppermost basement to help keep the hole open for subsequent monitoring and fluid sampling. The original CORK installed in Hole 1026B included a data logger, pressure sensors, thermistors at multiple depths, and a fluid sampler; all were recovered in 1999 except for the fluid sampler and sinker bar, which were stuck in the hole. Prior to the initial CORK installation in 1996, the hole produced water at a rate of $\sim 100 \mathrm{~L} / \mathrm{min}$ (Fisher et al., 1997); after the CORK installation, flow persisted at $\sim 3 \mathrm{~L} / \mathrm{min}$ until a $1 / 2$ inch valve was opened for microbiological sampling in 1997, at which time flow increased to $\sim 8 \mathrm{~L} / \mathrm{min}$ (Davis and Becker, 2002). When the original data logger was removed in 1999, warm $\left(\sim 64^{\circ} \mathrm{C}\right)$ altered basement fluid flowed rapidly (at an unknown rate) up through the 4 inch inside diameter (ID) logger landing seat until the full CORK body was replaced during Expedition 301 in summer 2004. The instrument string deployed in the new Hole 1026B CORK was recovered and replaced with a new thermistor string, fluid samplers, and microbio- 
logical growth experiments in 2008. The loggers for the thermistor string and the pressure gauges were connected to the NEPTUNE cable system in 2009, and both are providing real-time data that are accessible through the Internet (www.neptunecanada.ca/). The Hole 1026B CORK is currently leaking with an uphole flow rate of $\sim 0.8 \mathrm{~L} / \mathrm{min}$. The cause of the present leak is unknown.

Also during Leg 168, Hole 1027C was drilled $2200 \mathrm{~m}$ east of Hole 1026C, where sediment thickness is $575 \mathrm{~m}$ above buried basement (Fig. F1). Hole 1027C penetrated to $632 \mathrm{mbsf}$. The upper part of the hole was cased through sediments and into uppermost basement, leaving $54 \mathrm{~m}$ of open hole. The open interval near the base of Hole 1027C comprises a diabase sill, intercalated sediments, and basalt breccia overlying $26 \mathrm{~m}$ of extrusive volcanic rocks (Shipboard Scientific Party, 1997). The CORK installed in Hole 1027C during Leg 168 included a data logger, pressure sensors, thermistors at multiple depths, and a fluid sampler. These instruments were retrieved in 1999 , and the pressure logging system was replaced. In contrast to Hole $1026 \mathrm{~B}$, Hole $1027 \mathrm{C}$ was naturally underpressured with respect to ambient hydrostatic conditions (Davis and Becker, 2002). Hole 1027C was fully sealed and recorded formation pressure until 2008, when an attempt was made to connect a new-generation pressure data logger to the hole using the Aeroquip connector on the fluid sampling line. The hydraulic coupling was incomplete, causing hydrostatic pressures to be recorded until the sampling valve was closed in 2009.

Site U1301 was positioned $1 \mathrm{~km}$ south-southwest of Hole 1026B, where sediment thickness is $260-265 \mathrm{~m}$ above a buried basement high (Fig. F1) (Expedition 301 Scientists, 2005b). Hole U1301A was drilled without coring to $370 \mathrm{mbsf}(107 \mathrm{msb})$. Casing of $103 / 4$ inch outside diameter (OD) was extended into the uppermost $15 \mathrm{~m}$ of basement, and the hole reached a maximum total depth of $107.5 \mathrm{msb}$. A depth check prior to CORK deployment in Hole U1301A revealed that much of the lower part of the hole had filled in with rocks from the rubbly formation around the hole (Expedition 301 Scientists, 2005b).

Hole U1301B was positioned $36 \mathrm{~m}$ away from Hole U1301A and penetrated to a total depth of $583 \mathrm{mbsf}$ (318 msb). Uppermost basement was drilled without coring, and 103/4 inch steel casing was installed to 85 msb. Basement was cored from 86 to $318 \mathrm{msb}$. The uppermost $100 \mathrm{~m}$ of the cored interval in Hole U1301B was irregular in diameter, often much larger than the maximum inflation diameter of packers to be used for hydrogeologic testing and CORK observatories. However, the lowermost $\sim 100 \mathrm{~m}$ of the hole was stable and to gauge, allowing collection of highquality wireline logs and providing several horizons suitable for setting drill string and CORK casing packers (Expedition 301 Scientists, 2005b).

Hole U1362A was positioned $235 \mathrm{~m}$ south-southwest of Hole 1026B (Fig. F1), where the sediment thickness is $236 \mathrm{~m}$. As at Site U1301, both sediment and uppermost basement were drilled and cased without coring, with $103 / 4$ inch casing installed to $72.5 \mathrm{msb}$. Hole U1362A was cored to $260 \mathrm{msb}$ and then drilled to $292 \mathrm{msb}$ to make sure there was sufficient open hole to emplace a multilevel CORK system. Prior to CORK installation this hole was logged with a single string of geophysical instruments and tested with a drill string packer to assess near-hole hydrogeologic properties (see the "Site U1362" chapter).

Hole U1362B was positioned $311 \mathrm{~m}$ south-southwest of Hole U1362A and $514 \mathrm{~m}$ north-northeast of Hole U1301B (Fig. F1), where sediment thickness is $242 \mathrm{~m}$. Hole U1362B was originally planned to be drilled close to Hole U1362A (as with Holes U1301A and U1301B), but because Hole U1301A continued to vent formation fluid as of the start of Expedition 327, the location of Hole U1362A was shifted to the south, closer to Site U1301. This should provide a better chance for recovery in Hole U1301A of fluids and tracers injected in Hole U1362B and will allow crustal conditions between Holes U1362A and U1362B (and between Holes U1362A and 1026B) to be assessed. Sediment and uppermost basement in Hole U1362B were drilled and cased without coring, with the base of the $103 / 4$ inch casing placed at 30 msb. Basement below the casing was drilled without coring to $117 \mathrm{msb}$ prior to a $24 \mathrm{~h}$ pumping and tracer injection experiment (Fisher, Cowen, et al.), followed by installation of a single-level CORK system with instrumentation (see the "Site U1362" chapter).

\section{Expedition 327 CORK holes and CORK mechanical and hydraulic features}

Creating ridge-flank basement borehole observatories during Expedition 327 began with setting a reentry cone at the seafloor and installing $53 \mathrm{~m}$ of largediameter conductor casing into the uppermost sediments (Fig. F2; Table T1). The conductor casing helps hold the reentry cone in position, preventing the cone from sinking in unconsolidated sediments until a longer casing string can be cemented at depth. The conductor casing deployed at Site U1362 (and at Site U1301 during Expedition 301) had a 20 inch OD. Once the cone and conductor casing 
were installed in the seafloor, a hole was drilled through the underlying sediment and into the top few meters of basement using an 18 $1 / 2$ inch OD tricone bit. Sixteen inch OD casing was installed and cemented to or across the sediment/basement interface. We subsequently drilled into basement with a $14 \%$ inch tricone bit to allow installation of a third casing string (103/4 inch OD) within upper basement. We omitted any attempt to core the uppermost basement section prior to casing it off because (1) uppermost basement tends to be rubbly and unstable in this area, contributing to difficulties with drilling, coring, and other operations, and (2) recovery within this interval tends to be poor. Hole U1362A was deepened by rotary coring once the $103 / 4$ inch casing string was installed and cemented into place, whereas Hole U1362B was deepened with a 97/8 inch tricone (noncoring) bit to make enough room for CORK installation.

Expedition 327 CORKs were built around a central $4 \frac{1}{2}$ inch OD casing system that extends deep below the seafloor into a previously drilled and cased borehole. The part of the CORK system that sits above the seafloor when installed, referred to as the "wellhead," was constructed from concentric $4 \frac{1}{2}$ and $10^{3} / 4$ inch casing sections, with parts of the larger casing omitted or cut away between horizontally oriented, 30 inch OD bulkheads (Fig. F3). Seafloor sampling and valve manifolds, sensor packages, data loggers, and samplers were arranged within three $1.5 \mathrm{~m}$ high bays, offset by $120^{\circ}$, and separated by vertical gussets. The gussets provide strength to the wellhead and help to guide the ship's camera system and the submersible platform around the bays during CORK installation and later operations, protecting instrumentation and valves. During Expedition 327, one bay was dedicated to monitoring and logging pressure data, another was dedicated to fluid sampling, and a third was dedicated for a flowmeter and to microbiological sampling or auxiliary pressure monitoring or other experiments. Cutouts on the bulkheads and gussets are designed to allow a submersible or ROV to hold on for stability and leverage, and signs attached to the gussets indicate the directions that valves should be turned during operation.

CORK systems are designed to hydraulically isolate the formation at depth from the overlying ocean, requiring the use of multiple seal components (Figs. F2, F4). The $10^{3 / 4}$ inch OD casing systems deployed in Holes U1362A and U1362B included three independent mechanisms for sealing the formation at depth and inside 16 inch casing. First, tapered casing seal rings were designed so that the $103 / 4$ inch casing would be sealed against the 16 inch casing immedi- ately upon installation, using rubber O-rings and metal sealing surfaces in the casing hangers held in place by gravity and a mechanical latch (Fig. F4A). Second, swellable packer elements were bonded to the outside of sections of 103/4 inch casing (Fig. F4B). These elements use an FSC-11 Freecap elastomer (developed by TAM International, www.tamintl.com/) that expands in contact with seawater and which had an initial external diameter of $143 / 4$ inches. Full expansion of the swellable packer elements to the inner diameter of the 16 inch casing (151/8 inch) will likely require several weeks to months. Thus, the swellable packer element does not provide a seal immediately following casing installation but should provide a reliable casing seal over subsequent months to years. Finally, both the 16 and $103 / 4$ inch casing strings in both Holes U1362A and U1362B were cemented using cement having a density of $15.9 \mathrm{lb} /$ gallon $(1.9 \mathrm{~kg} / \mathrm{L})$. One-inch square pieces of cellophane ("Cello Flake") were added to the cement to clog pores and fractures adjacent to the borehole (lost circulation material [LCM]). In addition, 1.6\% $\mathrm{CaCl}_{2}$ was added to the cement as a setting accelerant. The use of LCM and an accelerant was new for scientific ocean drilling and was considered necessary given the difficulty of achieving cement objectives during earlier work in fractured ocean crust. Cement was deployed around the shoe of the $10^{3 / 4}$ inch casing without a cement retainer by backfilling the hole after the casing was landed and latched mechanically into place.

The use of a casing seal ring (Fig. F4A) might have prevented the flow of fluid and cement up the annulus between $103 / 4$ inch casing and the borehole wall, but it seems likely that the extremely fractured, rubbly, and permeable formation allowed significant lateral flow of cement near the base of the hole. Although this cement may not have formed a complete hydrologic seal between the $103 / 4$ inch casing and the formation, the cement should have helped to separate the main borehole area from the dead (annular) space outside the 103/4 inch casing, and this should improve the quality of future geochemical and microbiological samples. If the cement also provides a hydrologic seal, this should additionally improve measurements of formation pressure, particularly transient responses to tides and seismic events. Postinstallation monitoring of pressure within the annular gap of the cased interval will allow quantitative assessment of the quality of the cement seal at depth.

The main CORK seal (Fig. F4C) is located at the base of the CORK wellhead, where it seals against the $103 / 4$ inch casing in the throat of the reentry cone. Holes were drilled and tapped through the CORK seal sub 
for packer inflation, pressure monitoring, and fluid sampling lines. Below the seal sub are crossover subs and $4 \frac{1}{2}$ inch casing that extends to depth below seafloor. The length of $4 \frac{1}{2}$ inch casing that hangs below the CORK body is adjustable at sea depending on hole depth and conditions, available joint lengths, and the dimensions of other CORK components.

Expedition 327 CORKs used two packer systems for sealing $4 \frac{1}{2}$ inch casing in the open hole and in casing (Fig. F4D, F4E). At each CORK packer depth, a hydraulic packer was deployed below a pair of swellable packer elements. The hydraulic packer, inflated by pumping seawater down the pipe once the CORK was lowered into position, was intended to provide an immediate seal, as needed for monitoring short-term formation pressure response and limiting the continued inflow of cold bottom water. The swellable packer elements should provide a reliable long-term seal but will take several months to expand against 103/4 inch casing or the wall of the open borehole. The final CORK seal component uses the weight of the top plug, instrument string, and a sinker bar to hold an O-ring against a tapered seal area in the top of the wellhead (Figs. F2, F4F).

Expedition 327 CORKs included multiple perforated and screened components to permit pressure monitoring and fluid sampling while protecting downhole instrumentation from basement collapse (Fig. F5). Three perforated drill collars were deployed above a bullnose and below the deepest inflatable packer in each hole, with lines of 2 inch holes separated by 9 inches running vertically up four sides of the collars (Fig. F5A, F5B). The collars provide weight needed to pull the lower end of the CORK into the hole during deployment. Additional sections of perforated $5 \frac{1}{2}$ inch casing were deployed above the collars, with lines of $1 \frac{1}{2}$ inch holes separated by 8 inches running vertically up four sides of the casing (Fig. F5C). The perforated collars and casing, bullnoses, and crossover subs needed to attach these components to the rest of the CORK casing string were coated internally with TK-34XT (Tuboscope, www.tuboscope.com/) and externally with Amerlock 400 (Amercoat, www.amercoatcanada.com/). Both of these epoxy-based compounds should reduce the extent of reaction between the steel collar and casing alloys and the warmed borehole fluids (Orcutt et al., 2010), improving our understanding of the composition and microbiology of subseafloor fluids.

Formation pressure is monitored and borehole fluids are sampled at the CORK wellheads using wire-wrap miniscreens installed at depth (Fig. F5D-F5F). Stainless steel screens are used for pressure monitoring and standard geochemical sampling, whereas micro- biological sampling is completed through titanium screens.

Three forms of tubing umbilical were prepared for use during Expedition 327 (Fig. F6). One plastic-jacketed flat pack contained two $1 / 4$ inch OD stainless steel tubes for pressure monitoring and a single $1 / 2$ inch OD hydraulic packer inflation line (Fig. F6A). A second plastic-jacketed flat pack contained three $1 / 2$ inch OD stainless steel tubes intended mainly for geochemical sampling (Fig. F6B). A final plastic and woven metal-jacketed umbilical was constructed around a $1 / 2$ inch polytetrafluoroethylene (PTFE) tube for use with microbiological sampling from the deepest monitored interval (Fig. F6C). Umbilical tubes were deployed as each CORK was constructed, from the bottom to the top, with tubes being passed through the inflatable and swellable packers as needed (Fig. F6D, F6E). Final connections were made at the top of the CORK casing, connecting sampling and monitoring lines to pigtails that were preinstalled to pass through the seafloor CORK seal (Fig. F6F).

Each CORK installed in Holes U1362A and U1362B included a lateral $4 \frac{1}{2}$ inch casing section that extended at a $\sim 20^{\circ}$ angle up from below the lower bulkhead (shown in Fig. F2), leading to the name "lateral CORK" or "L-CORK." The angled lateral casing penetrated the lower bulkhead with an offset of $91 / 4$ inches from the CORK center line and was terminated at the top with a large-diameter (4 inch) ball valve (Fig. F7). The ball valve was modified to include welded valve handle stops, and holes were drilled through the valve casing to avoid trapping air in dead space around the ball that could lead to development of a large differential pressure and damage during deployment. A custom ring clamp on top of the ball was deployed with a dust cover to prevent fouling of the valve. The dust cover will be removed and replaced with a flowmeter at one of the Expedition 327 CORKs in summer 2011 so that when the ball valve is opened the natural overpressure in basement will drive fluid out of the borehole at an anticipated rate of 5-10 L/s. This flow will be allowed to continue for at least 12 months, comprising a controlled cross-hole experiment that will allow assessment of directional basement properties at a crustal scale. Because we wished to be able to run the longterm free-flow experiment from either of the new CORKs, no lower plug was placed on the instrument strings deployed in these observatories. However, plug seats ( $33 / 8$ inch ID) were placed between the swellable and inflatable packer elements at depth in both systems so that plugs could be installed in the future if this were desired following recovery of the initial instrument strings. 
Unlike Expedition 301 CORKs, which were deployed with most valves open and flowing freely, the Expedition 327 CORKs were deployed with valves either closed (in flowmeter/microbiology and geochemistry bays) or sealed and being monitored (in the pressure bay). No submersible or ROV expedition was planned to install instruments immediately after Expedition 327, and we wished to have a sustained period of sealed conditions to allow recovery of formation pressure to a predrilling state.

\section{Expedition 327 CORK sensors and sampling}

\section{Pressure}

Pressure measurement and logging systems deployed during Expedition 327 were built into frames designed to slide onto mounts within one of the three measurement and sampling bays in the CORK wellheads (Fig. F8). These systems share characteristics with those deployed following CORK installation during Expedition 301. Electronics and batteries are housed in a cylindrical pressure case, and communication with a computer for programming and data download is accomplished using an underwater mateable connector (Teledyne ODI). Instruments deployed during Expedition 327 include three absolute pressure gauges (Paroscientific model 8B-7000) to monitor conditions at multiple depth intervals and the seafloor. The loggers can sample at time intervals as short as $1 \mathrm{~s}$, and sensors have temperature-compensated pressure resolution on the order of $2 \mathrm{~Pa}(0.2$ $\mathrm{mm}$ water), similar to those deployed on Expedition 301 CORK systems (Fisher et al., 2005). Loggers were configured to sample at a 1 min interval on deployment. Pressure gauges are connected with 1/16 inch OD stainless steel lines to hydraulic couplers attached near the base of the system frame, and the couplers are inserted into matching receptacles mounted near the base of the pressure bay. The receptacles are connected with $1 / 8$ inch stainless steel lines to three-way valves mounted in the same wellhead bay, then down through the seafloor CORK seal and to $1 / 4$ inch stainless steel lines that extend to depth.

CORK data loggers communicate with a RS-422 protocol at speeds of up to $230 \mathrm{~kb} / \mathrm{s}$. Data from pre-Expedition 327 CORKs that use the same connector and communications systems were downloaded and the loggers were reprogrammed using the submersible DSRV Alvin and ROVs ROPOS and Jason. As described earlier, the pressure logger on the CORK installed in Hole 1026B is currently connected to the NEPTUNE Canada network (www.neptunecan- ada.ca/). Expedition 327 and other Expedition 301 CORKs are similarly "NEPTUNE ready," and hopefully more installations will go online in the near future.

Several days prior to each Expedition 327 CORK deployment, pressure monitoring lines were tested for hydraulic integrity from below the CORK seafloor seal up to the data loggers. For each CORK, the pressure measurement frame was installed in the wellhead, placing the hydraulic couplers in the receptacles. A fluid injection and pressure monitoring manifold was connected to tubing pigtails below the CORK seal. The fittings connecting $1 / 16$ inch monitoring lines to the pressure gauges were loosened, and the lines were de-aired by pumping freshwater through the lines for 10-20 min at 40-50 psi. The fittings were tightened, pressure was shut in at the testing manifold, and conditions were monitored using the data logger to verify that a complete seal was sustained. Once system integrity was verified, the data logger remained installed in the wellhead until the CORK was deployed.

Additional de-airing of pressure monitoring lines was completed during the final stages of CORK deployment, after all monitoring line connections were complete. Screw-cap purge valves were installed at high points for each pressure line (when CORK was positioned vertically), located behind the control valves in the wellhead (Fig. F8D). After each CORK wellhead was lowered through the rig floor, it was held over the moonpool and the purge valves were loosened; the wellhead was then lowered several meters below the water surface. After waiting 10 min for air in the pressure lines to escape, the wellhead was raised and the purge valves were tightened. Three-way valves in the wellheads are configured for each pressure gauge so that it can be set to monitor conditions at either depth or at the seafloor. Monitoring intervals and three-way valve configurations for Expedition 327 CORKs, as deployed, are described later.

\section{Temperature}

Autonomous temperature sensors and data loggers deployed in Expedition 327 CORKs are similar to those deployed during Expedition 301 (Fig. F9). We elected to use autonomous loggers rather than a preinstrumented thermistor cable because (a) we could not be certain as to the desired final space-out of thermistor sensors and other components until the holes were completed to their final depths; (b) thermistor cables are considerably more expensive than autonomous loggers; (c) thermistor cables require electrical pass-throughs for plugs and pressure cases, adding to the system's complexity and 
opportunity for failure; and (d) use of a braided Spectra line makes it easier to attach plugs, weights, and fluid and microbiological sampler systems. We also needed to monitor temperatures at the depths of the osmotic samplers because their sampling rates depend on the temperature-dependent viscosity of seawater, and this requires use of autonomous temperature loggers.

We purchased modified versions of two commercial temperature logging tools for use with the Expedition 327 CORKs (Fig. F9A). Two sets of instruments were built by Antares Datensysteme $\mathrm{GmbH}$ (www.antares-geo.de/), the manufacturer of tools used in CORKs deployed during Leg 205 and Expedition 301 (Pfender, 2002, number 1481). These tools differ from standard commercial instruments in being slightly wider and having double O-ring seals and a 5 y lithium battery. Antares tools used during Expedition 301 (purchased in 2004) had a working range of $\sim 41^{\circ}-100^{\circ} \mathrm{C}$, which allowed us to maintain nominal tool resolution of $1 \mathrm{mK}$ across the range of temperatures anticipated in basement $\left(\leq 60^{\circ} \mathrm{C}\right)$. Five of these tools, recovered from Holes $1026 \mathrm{~B}$ and U1301A following a 4 y deployment, were refurbished at the factory and recalibrated in preparation for Expedition 327. In addition, 18 of a newer generation of Antares instruments having a working range of $\sim 1^{\circ}-100^{\circ} \mathrm{C}$ were purchased and calibrated in 2009 . All of these tools are programmed and operated using a through-case serial connection, with operating software run on a PC, so that the pressure cases need never be opened to operate the tools, check battery power, or access data.

The other temperature tools prepared for Expedition 327 were constructed by Onset Computer Corporation (www.onsetcomp.com/), HOBO model U12015, modified with a titanium pressure case and long-life battery for use in the deep sea. The Onset tools have a working range of $-40^{\circ}-100^{\circ} \mathrm{C}$ but a lower resolution $\left(0.02^{\circ}-0.1^{\circ} \mathrm{C}\right.$ across their working range) than the Antares tools because they use 12-bit rather than 16-bit analog/digital (A/D) conversion. Like the Antares tools, the Onset tools are programmed and data are accessed using software on a PC, but the end of the pressure case for the Onset tools must be opened to allow communication with a computer.

All of the Expedition 327 temperature tools were calibrated in 2009 (Fig. F10). We used a stirred-fluid temperature calibration bath (Hart Scientific model 7011) capable of maintaining temperature stability of $\pm 0.001^{\circ}-0.01^{\circ} \mathrm{C}$ over a temperature range of $-5^{\circ}-$ $100^{\circ} \mathrm{C}$ and a National Institute of Standards and Technology (NIST)-traceable resistance-temperature device (RTD) probe (Hart Scientific model 1521) with an accuracy of $\pm 0.001^{\circ} \mathrm{C}$. The RTD and digital readout were recalibrated to factory specifications in 2008. Calibration of the Onset and newer Antares tools was completed at 11 temperatures across a range of $\sim 2^{\circ}-80^{\circ} \mathrm{C}$. The older Antares tools were calibrated at seven temperatures across a range of $\sim 42^{\circ}-$ $80^{\circ} \mathrm{C}$.

Calibration in 2009 improved the accuracy of all tools relative to factory values. Onset tools have typical root-mean-squared (RMS) errors of $0.01^{\circ} \mathrm{C}$ during calibration (Fig. F10A), based on a third-order polynomial fit of apparent (factory) temperatures to reference probe temperatures. However, this is for a stable bath with temperatures measured every $10 \mathrm{~s}$ for $30-40$ min, which allows averaging of 180-240 measurements to improve the effective resolution. In practice, the digital resolution of individual measurements with these tools varies from $0.02^{\circ} \mathrm{C}$ near $2^{\circ} \mathrm{C}$ to $0.1^{\circ} \mathrm{C}$ near $65^{\circ} \mathrm{C}$. Both generations of Antares tools have typical calibrated RMS errors of $0.001^{\circ}-0.003^{\circ} \mathrm{C}$ (Fig. F10B, F10C) and similar resolutions across their full range of operation. For field deployment in CORKs, temperature tools were programmed to record data every 90-120 min, so as to preserve battery power and memory for 4-5 $\mathrm{y}$. If borehole conditions are relatively stable, tool resolution may be improved by averaging values measured over several days.

Most of the temperature tools deployed in CORKs during Expedition 327 were housed inside perforated sections of hydraulic hose, which was spliced to the Spectra cable and covered with electrical tape prior to instrument string deployment (Fig. F9B, F9C). This hose helps to protect the temperature instruments from damage during string deployment and recovery. Additional temperature tools were deployed inside polyvinyl chloride (PVC) housings containing OsmoSamplers and microbiological growth systems. The distribution of individual temperature tools on CORK instrument strings is described in "Configuration of Expedition 327 CORKs."

\section{Continuous fluid sampling}

Instrument strings deployed within Expedition 327 CORKs included multiple downhole OsmoSampler systems (Jannasch et al., 2004) built around a common design (Wheat et al.) (Fig. F11). CORK systems deployed during earlier expeditions also included wellhead OsmoSamplers, as described later. No wellhead OsmoSamplers were deployed on Expedition 327 CORKs because these new CORKs use $1 / 2$ inch sampling lines that are intended to flow freely (discharging much more fluid than is captured by OsmoSamplers). We wished to leave these CORKs 
sealed to allow recovery following drilling and assessment of regional pressure conditions prior to the start of a long-term flow experiment in summer 2011.

The borehole OsmoSampler systems were designed to pass through drill pipe and the inner CORK casing, and thus could have an outer diameter no larger than the smallest restriction imposed by the lowermost plug seat $\left(3 \frac{3}{8}\right.$ inch ID) in the casing string. The outer housing of the pumps was made of clear PVC, whereas most of the other pump parts were made of standard gray PVC. Each of the pump pieces was sealed with double O-ring seals, and the membranes were held in place with a single O-ring and a twopart epoxy (Hysol ES1902, www.henkelna.com/). Membrane configuration differed depending on the application: pumps contained either one or two Alzet 2ML1 membranes or one Alzet 2ML4 membrane (www.alzet.com/). The salt gradient across the membrane was created using excess noniodized table salt $(\mathrm{NaCl})$ supersaturated in water on one side of the membrane and deionized (18.2 $\mathrm{M} \Omega$ ) water on the other side (Fig. F11B).

The pumps were mounted on a central $1 / 2$ inch OD stainless steel rod used to provide strength for the assembly, which consisted of threaded end-caps, the central rod, pump(s), sample coils, PVC connectors for stability, and in some cases temperature loggers, as described earlier. Each component fit within a 27/8 inch OD clear PVC tube, used to protect the assembly during deployment and recovery. The OsmoSampler assemblies were connected in a series using $1 / 2$ inch galvanized shackles with PVC isolators.

Six kinds of OsmoSamplers were deployed during Expedition 327: standard, gas tight, acid addition, BioOsmoSampling System (BOSS), microbiological enrichment, and microbiological growth (MBIO). Each OsmoSampler was intended for a deployment as long as $6 \mathrm{y}$. These instrument systems are described briefly in the rest of this section and in greater detail elsewhere in this volume (Wheat et al.). Configurations and depths of individual instruments deployed during Expedition 327 are described in "Configuration of Expedition 327 CORKs," below.

A standard OsmoSampler assembly consists of a pump with a single Alzet 2ML1 membrane and four $305 \mathrm{~m}$ long PTFE sample coils (1.2 mm ID). This configuration can sample $\sim 3.5 \mathrm{~mL}$ of fluid per week at an anticipated basement temperature of $60^{\circ}-70^{\circ} \mathrm{C}$. Once recovered, fluids from the standard assembly are analyzed for major and minor ions.
The gas-tight assembly is similar to the standard assembly but uses four copper sample coils (Fig. F11C) to minimize diffusional gas exchange. For the Expedition 327 instruments, this will be important both for natural gases and for $\mathrm{SF}_{6}$, which was one of the tracers injected in Hole U1362B during the $24 \mathrm{~h}$ pumping experiment (Fisher, Cowen, et al.).

The acid addition assembly consists of (from bottom to top) a PTFE sample coil filled with deionized water, a single 2ML4 membrane pump, a PTFE coil filled with dilute acid $(20 \mathrm{~mL}$ of subboiled $6 \mathrm{~N} \mathrm{HCl}$ in $500 \mathrm{~mL} 18.2 \mathrm{M} \Omega$ water), a T-connector with one branch open to borehole fluids and the other connected to four PTFE sample coils, and a single 2ML1 membrane pump. Thus, the lower pump, which has a pump rate one-fourth that of the upper pump, forces dilute acid into the T-connector, where it mixes with borehole fluids that are subsequently stored in the four upper sample coils. This acid addition helps to stabilize redox-sensitive dissolved metals and reactive ions, ideal for shore-based measurements of trace elements in seawater and reacted formation fluids.

The fourth and fifth assemblies have physical configurations similar to that of the acid addition assembly. The BOSS assembly has a coil that discharges $20 \mu \mathrm{L}$ of saturated $\mathrm{HgCl}_{2}$ in $500 \mathrm{~mL}$ of $18.2 \mathrm{M} \Omega$ water, rather than the dilute acid of the acid addition coil. The BOSS assembly is designed to arrest microbial metabolic processes while maintaining cell structure for shore-based microbial assays. The microbiological enrichment assembly injects a fluid having a composition dependent on specific experimental goals. For Expedition 327, the enrichment assembly injects artificial borehole media (based on borehole fluid compositions described by Wheat and Mottl [2000]) with $1 \mathrm{mM} \mathrm{NaH}{ }^{13} \mathrm{CO}_{3}$ and $0.2 \mathrm{mM}$ $\mathrm{NaH}^{12} \mathrm{CO}_{3}$ to track autotrophic incorporation of ${ }^{13} \mathrm{C}$-labeled substrates. The enrichment assembly also contains a single microbial growth chamber, described below, so that microorganisms that fix dissolved carbon can be identified and quantified during shore-based analyses.

The MBIO assembly consists of a series of microbial growth chambers (Orcutt et al., 2010, 2011), described in the next section, eight PTFE sample coils, and a pump with two 2ML1 membranes. This configuration allows more fluid to pass through the chambers and be recovered than would be provided by the standard assembly. By comparing this fluid to that collected with the standard assembly, researchers will be able to document compositional changes 
related to microbial and inorganic reactions within the microbial growth incubators.

\section{Microbiological growth incubators}

Newly designed Flow-through Osmo Colonization Systems (FLOCS) (Orcutt et al., 2010) were deployed in Expedition 327 CORKs (Fig. F12). Like the Expedition 301 passive colonization experiments and flow cells (Fisher et al., 2005; Orcutt et al., 2011; Smith et al., submitted), FLOCS contain series of presterilized chambers packed with colonization substrate. Some chambers are connected to osmotic pumps that introduce a slow and steady flow of formation fluids, whereas other chambers are passively open to the formation. Microorganisms in the borehole fluids may preferentially colonize various rock and mineral substrates on the basis of favored mineral-fluid redox reactions (e.g., Edwards et al., 2003). Connection of the outflow of the chambers to an OsmoSampler sampling coil provides a temporal record of chemical changes during deployment, and comparison of these fluids to those collected with standard OsmoSampler fluids may elucidate biogeochemical reactions occurring within the chambers.

A modified FLOCS experiment, coupled to an enrichment-injection OsmoSampler, was deployed during Expedition 327 (Fig. F12B, F12E). The enrichment OsmoSampler was configured to deliver a slow and steady supply of ${ }^{13} \mathrm{C}$-labeled bicarbonate to act as a tracer of potential autotrophic reactions that may occur during mineral colonization. Similar to stable isotope probing methods used elsewhere (Boschker et al., 1998; Ginige et al., 2004; Orphan et al., 2001; Radajewski et al., 2000), the incorporation of ${ }^{13} \mathrm{C}$-labeled bicarbonate into biomass during growth will allow autotrophic metabolism to be tracked using molecular techniques in the laboratory. Experiments such as this could help to identify the unknown autotrophic members of microbial communities in oceanic crust that support the base of the food web in this poorly understood biome.

\section{Configuration of Expedition 327 CORKs}

In this section we document the configuration of two new CORKs and associated instrumentation deployed during Expedition 327. In the next section we summarize the status of CORK systems deployed during Leg 168 and Expedition 301 and subsequently modified through drillship and/or seafloor servicing using a submersible or ROV.

\section{Hole U1362A}

The configuration of the CORK deployed in Hole U1362A is summarized in Figure F13 and Tables T1, T2, T3, T4, and T5. An engineering drawing showing hole, casing, and CORK configurations in Hole $\mathrm{U} 1362 \mathrm{~A}$ is included with this volume (see Fig. F3 in the "Site U1362" chapter and COMPLTN in "Supplementary material"). The Hole U1362A CORK was designed to monitor two basement intervals: a deeper interval extending from the top of the "ingauge" section of hole to total depth and a shallower interval extending from the base of $10^{3 / 4}$ inch casing to the top of the packers at the top of the deeper interval. The initial design for Hole U1362A was based on experience gained drilling Hole U1301B (800 m to the south-southwest; Fig. F1), which suggested that although the uppermost $\sim 200 \mathrm{~m}$ of basement would be rubbly, hole conditions should improve at greater depth. In fact, drilling conditions and the rate of penetration, core recovery, and wireline logging data from Hole U1362A (see the "Site U1362" and "Expedition 327 summary" chapters) all indicated that the shallow interval of rubbly basement extended to a somewhat greater depth in Hole U1362A than in Hole U1301B. The interval of consistently better conditions began near 450 mbsf ( $220 \mathrm{msb}$ ), but when this was determined there was not enough open hole below this depth to confidently deploy the complete CORK system. For this reason, the open hole CORK packers that make up the boundary between deeper and shallower basement intervals were placed in an in-gauge section at 419-429 mbsf ( 183-193 msb) (Fig. F13). When the Hole U1362A CORK was deployed there was $\sim 49 \mathrm{~m}$ of open hole below the end of the CORK bullnose.

Downhole OsmoSamplers, microbiological experiments, and temperature loggers were deployed inside the Hole U1362A CORK. The geochemical and microbiological instruments are located entirely within perforated and coated drill collars and casing, where they are monitoring the deeper of the two isolated intervals. Temperature loggers are located within this interval and at shallower depths inside nonperforated casing in basement and sediments (Fig. F13; Tables T3, T4).

In addition to monitoring two basement intervals, the pressure valves in the Hole U1362A CORK wellhead were configured at deployment to continuously monitor seafloor pressure as a means to assess sensor drift (Fig. F14A). The gauge currently monitoring seafloor pressure can be switched to spotcheck pressure within the annular gap between 16 and $10^{3 / 4}$ inch casing during CORK servicing. This 
gap should be sealed at the top by a casing hanger seal and a swellable casing packer (Fig. F4A, F4B) and at the base of the $103 / 4$ inch casing by cement (Fig. F2). Even if the cement seal at depth is incomplete, the top seals should still be sufficient to determine pressure conditions in upper basement.

Geochemical sampling valves on the Hole U1362A CORK wellhead were deployed closed (Fig. F14B), as were the large-diameter flowmeter valve and microbiology sampling valves (Fig. F14C). Seafloor OsmoSampler systems will be attached in the geochemistry bay and these valves will be opened during future CORK servicing expeditions, and short-term or long-term sampling using the microbiology valves can also be initiated. We are currently not planning to open the ball valve in the flowmeter bay on the Hole U1362A CORK during summer 2011 operations, but a final determination will be made during these dives once the status of the full CORK network is verified.

\section{Hole U1362B}

The configuration of the CORK deployed in Hole U1362B is summarized in Figure F15 and Tables T1, T2, T3, T4, and T5. An engineering drawing showing hole, casing, and CORK configurations in Hole $\mathrm{U} 1362 \mathrm{~A}$ is included with this volume (see Fig. F4 in the "Site U1362" chapter and COMPLTN in "Supplementary material"). The Hole U1362B CORK was designed to monitor a single basement interval that partly overlaps the shallowest interval monitored in Hole U1362A (Fig. F13; Table T1). Because Hole U1362B was not planned to penetrate to a depth sufficient to create an in-gauge section of 978 inch hole, packers were set only inside $103 / 4$ inch casing, but perforated collars and casing extended beyond this depth into basement drilled using 143/4 and 97/8 inch tricone bits (Fig. F15). When the Hole U1362B CORK was deployed there was $\sim 36$ m of open hole below the end of the CORK bullnose.

Downhole OsmoSamplers and microbiological experiments were deployed entirely within perforated and coated drill collars and casing. Temperature loggers are located within this interval and at shallower depths inside nonperforated casing in basement and sediments (Fig. F15; Tables T3, T4).

In addition to monitoring a single basement interval, the Hole U1362B CORK was configured on deployment to continuously monitor pressure within the annular gap between 16 and 103/4 inch casing (Figs. F15, F16A). Both gauges are run through valves that can be switched to spot-check seafloor pressure during periodic servicing as a means to assess instrument drift. In addition, a third (dedicated) gauge was configured in the Hole U1362B CORK to monitor seafloor pressure.

Geochemical sampling valves on the wellhead were deployed closed (Fig. F16B), as were the large-diameter flowmeter valve and microbiology sampling valves (Fig. F16C). OsmoSampling systems will be attached in the geochemistry bay and these valves will be opened during future CORK servicing expeditions, and short-term or long-term sampling using the microbiology valves can also be initiated. We currently plan to open the large-diameter ball valve on the Hole U1362B CORK during summer 2011 operations and attach an autonomous flowmeter to determine the rate of fluid egress from the wellhead for the following 1-2 y. The pressure response in basement to this free-flow perturbation will be monitored using CORKs at Sites 1026, 1027, and U1301 and in Hole U1362A.

\section{Status of CORKs installed before Expedition 327}

CORKs installed prior to Expedition 327 were visited periodically following Leg 168 and Expedition 301 to download data, collect samples, and swap out instrumentation as needed to be prepared for Expedition 327. The last CORK servicing visit before Expedition 327 was in June-July 2010 during R/V Atlantis Expedition AT15-66, using the ROV Jason for seafloor operations. In this section we report on the status of CORKs installed before Expedition 327, as of the end of Expedition AT15-66. Operations involved in creating these CORKs, as well as details of hole completion, servicing operations, and CORK configuration through 2004 are described elsewhere (Becker and Davis, 2005; Davis and Becker, 2004; Expedition 301 Scientists, 2005a, 2005b; Fisher et al., 2005; Shipboard Scientific Party, 1997).

\section{Hole U1301A}

The Hole U1301A CORK was installed without a casing seal between the 16 and 103/4 inch casing strings, and cementing the $10^{3 / 4}$ inch casing to the formation at depth was unsuccessful, so this CORK was not sealed at deployment. As a result, bottom seawater flowed through holes in the 103/4 inch casing hanger in the throat of the cone and down the annulus between the casing strings (Fisher et al., 2008). Flow down the hole spontaneously changed direction in fall 2007 after summer 2007 CORK servicing operations, and shimmering water was observed to be flowing from around the wellhead during a summer 2008 servicing expedition (Wheat et al., 2010). Although still not sealed, the flow of water from the 
formation and into the Hole U1301A CORK represents an improvement in conditions for this observatory system, as it provides an opportunity to sample formation fluids and assess the nature of in situ microbiological communities (Orcutt et al., 2011; Wheat et al., 2010). The spontaneous change in flow direction following several years of fluid flow down the hole and into the formation also places constraints on formation properties (Davis et al., 2010). However, the lack of a seafloor seal and the continued flow of formation fluid from Hole U1301A prevents assessment of basement pressure conditions around the hole and could make the interpretation of cross-hole response more complex during the long-term free-flow experiment. An attempt was made to seal this CORK with cement during Expedition 321T in summer 2009 (Fisher and Expedition 321T Scientific Party, 2010), but subsequent observations during dive operations in summer 2009 and 2010 indicate that the hole remained unsealed.

Although cement was observed to have completely filled the cone immediately after being injected during Expedition 321T, the current appearance of the hole indicates that much of the cement drained away, presumably through the same gaps through which warm formation fluid currently flows (Fig. F17). Although it is not sealed, the Hole U1301A CORK is instrumented at the wellhead and downhole. A pressure logging system with two gauges monitors pressures at two depths, immediately below the seafloor and below the packer near the base of $103 / 4$ inch casing. Both of these gauges currently show hydrostatic conditions superimposed with noise associated with the turbulent flow of warm formation fluid up and around the wellhead.

The downhole instrument string in Hole U1301A was recovered and replaced using the submersible $\mathrm{Al}$ vin in summer 2009 (Tables T3, T4). The new string comprises (from top to bottom) a top plug, $3 / 8$ inch Spectra cable, a middle sinker bar $(35 \mathrm{lb}), 3 / 8$ inch Spectra cable, a bottom plug, three OsmoSampler systems (gas tight, MBIO, and acid addition), and a lower sinker bar (100 lb). Five autonomous temperature data loggers are deployed on the Spectra cable, and another three are deployed inside OsmoSampler systems (Table T3). The instrument string components hung below the lower plug are short enough to fit entirely within slotted (but uncoated) casing between the lower plug and the end of the bullnose at the base of $4 \frac{1}{2}$ inch CORK casing.

Three seafloor OsmoSampler systems were deployed on the Hole U1301A wellhead in summer 2010 (Fig. F17C, F17D), and all are connected to the open basement interval at depth: one with two $\sim 300 \mathrm{~m}$ long PTFE sampling coils, one with two $\sim 300 \mathrm{~m}$ long PTFE coils and five FLOCS chambers, and one with two $\sim 300 \mathrm{~m}$ long copper-tubing coils. The PTFE-coil OsmoSampler was installed in the left side of the bay on the left sample port and is controlled by Valve 4 . The FLOCS OsmoSampler was installed on the right side of the bay on the right sample port and is controlled by Valve 3 . The copper OsmoSampler was installed in the center of the bay and is supplied by the right sample port, controlled by Valve 2. At the end of summer 2010 operations, Valves 2, 3, and 4 were open and Valves 1, 5, and 6 were closed (Fig. F17D). The end of the T-handle on Valve 6 broke off during recovery of an older OsmoSampler that had been installed on the right sample port, but fortunately this occurred after the valve had been closed.

A geomicrobiology sensor and fluid sampling system ("GeoMICROBE" instrument sled, Wheat et al.) was deployed with the sample inlet connected to the lower of two Aeroquip connectors in the microbiology sampling bay (Fig. F17E). This system is programmed to pull $550 \mathrm{~mL}$ individual fluid samples and filter samples collected from volumes of $8 \mathrm{~L}$ from the borehole at $\sim 3$ week intervals until the system's recovery in summer 2011. These samples will be useful in assessing the return of borehole conditions to a predrilling state, the nature of formation fluids at depth, and the timing and extent of tracer arrival following injection into Hole U1362B during Expedition 327 (Fisher, Cowen, et al.). The GeoMICROBE instrument sled is also equipped with a suite of in-line fluid sensors (e.g., temperature, flow, oxygen, $\mathrm{pH}$, and electrode potential) and an electrochemical (voltametry) analyzer that operate simultaneously with fluid collection and filtering. A weight stack that had previously been deployed on the top plug of Hole U1301B was moved to Hole U1301A in summer 2010, clearing the former wellhead for instrument string recovery and providing additional downward force on the top plug (Fig. F17F).

\section{Hole U1301B}

The Hole U1301B CORK was also deployed during Expedition 301 without casing seals and with incomplete cementing at depth, leaving the borehole observatory unsealed. This resulted in long-term flow down Hole U1301B that led to a pressure perturbation in the surrounding crust that was resolved by formation pressure monitoring below the Hole 1027C CORK, $2.4 \mathrm{~km}$ to the east (Davis et al., 2010; Fisher et al., 2008). Unlike Hole U1301A, downward flow into Hole U1301B did not reverse spontaneously, most likely because this hole is deeper and has a greater open basement interval, requiring a larger excess formation pressure to overcome the hydrothermal siphon created by the imposition of cold 
bottom water in the hole during drilling and other operations. Two attempts were made to cement the cone around the CORK wellhead in Hole U1301B using Alvin and a seafloor cement delivery system in summer 2006 and 2007, but neither of these efforts was successful, although there was an observable pressure response as a result of cement delivery to the cone in summer 2007. The cone around the CORK wellhead was filled with cement during Expedition 321T, and on the basis of seafloor observations made during servicing in summer 2009 and 2010 , much of the cement remained in the cone.

Pressure data downloaded 3 weeks after cementing in summer 2009 and 2010, prior to Expedition 327, and thermal data collected from Hole U1301B during Expedition 327 (see the "Site U1301" chapter) suggest that Expedition 321T cementing was successful in sealing this borehole observatory. However, pressure records from the deepest two intervals in basement indicate that the pressure monitoring lines were blocked soon after cementing operations. Anomalously high pressures detected within these gauges (400-1200 $\mathrm{kPa}$ in excess of hydrostatic pressures measured in summer 2010) appear to result from the heating of sealed parts of the pressure monitoring system rather than from actual formation conditions. In contrast, pressure data from the shallowest monitoring interval in Hole U1301B shows evidence of a continuing return to superhydrostatic conditions, following a 5 y thermal and pressure perturbation associated with rapid downhole flow.

Three OsmoSamplers were recovered from the wellhead in Hole U1301B in summer 2010 prior to Expedition 327, and three new OsmoSamplers were deployed (Fig. F18). The system deployed in the center of the bay uses two $\sim 300 \mathrm{~m}$ long copper coils and is attached to Valve 5, which samples formation fluids from the deepest basement monitoring interval. The other two OsmoSamplers each consist of an osmotic pump and two $\sim 300 \mathrm{~m}$ long PTFE coils attached to the right sample port, as well as four FLOCS chambers attached to the left sample port. The left-side OsmoSampler was plumbed to the deep formation interval using Valves 1 and 4, and the right-side OsmoSampler was plumbed to the intermediate depth interval using Valves 3 and 6 . At the end of the summer 2010 dive series, Valves 1, 3, 4, 5, and 6 were open and Valve 2 was closed (Fig. F18D).

Part of the original instrument string deployed in Hole U1301B was recovered and replaced during Expedition 327 (see the "Site U1301" chapter). The new string comprises a $51 \mathrm{~m}$ Spectra cable on which three autonomous temperature probes and a $200 \mathrm{lb}$ sinker bar are mounted (Table T3). These instruments were installed to monitor the continuing re- turn of Hole U1301B to predrilling conditions following a long period of disturbance associated with rapid downhole flow of cold bottom water.

\section{Hole 1026B}

The instrument string deployed in Hole 1026B during Expedition 301 was recovered in summer 2008 and replaced with several OsmoSampler packages suspended at the base of a thermistor cable. The thermistor cable has sensors with millikelvin temperature resolution at $14 \mathrm{~m}$ spacing and provides data in real time through the NEPTUNE Canada regional network (www.neptunecanada.ca/). The Hole 1026B pressure data logger, deployed using the submersible Alvin in 2007, is also transmitting data through the NEPTUNE Canada network (Fig. F19). Both systems are fully operational; seafloor and borehole pressure and seafloor temperature are measured at a frequency of $1 \mathrm{~Hz}$, and borehole temperatures at 16 depths are measured at a frequency of once per $0.5 \mathrm{~h}$ (programmable to once per $10 \mathrm{~s}$ ). Formation pressure is sampled at a single depth interval in uppermost basement, and the thermistor cable monitors conditions within the sedimentary section down to $200 \mathrm{mbsf}$ because a drill pipe liner installed during Leg 168 extends upward from basement and into the $103 / 4$ inch casing, preventing instrumentation inside the CORK from extending across the sediment/basement interface. Bacterial growth and mineral precipitation on the Hole 1026B CORK wellhead and variations and trends in downhole pressures and temperatures following installation of the new thermistor cable in 2008 suggest that Hole $1026 \mathrm{~B}$ is incompletely sealed, once again.

Three new and refurbished OsmoSampler systems were deployed on the Hole 1026B CORK wellhead during dive operations in summer 2010. A pump with two $\sim 300 \mathrm{~m}$ long copper coils was placed on the left side of the sampling bay, a pump with two $\sim 300 \mathrm{~m}$ long PTFE coils and three FLOCS chambers in series was placed in the center of the bay, and a pump with two $\sim 300 \mathrm{~m}$ long PTFE coils was placed on the right side of the bay. These systems are plumbed through Valves 4, 5, and 6, respectively, which were left open as of the end of dive operations. Valves 1, 2, and 3 remained closed (Fig. F19F).

\section{Hole 1027C}

Unfortunately, it was not possible to recover the old CORK, deepen the hole, and install a new CORK system during Expedition 327, as was originally planned (see the "Site 1027" chapter), and the old CORK remains installed in this hole. Pressure in this CORK was monitored with an earlier generation data logger and gauge system, which also served as a top 
plug for the wellhead. This system had been connected to a battery pack and communications interface (using the same underwater mateable connector as that used by more recent CORK systems) placed on the landing platform in summer 2007. The battery pack and communications interface were disconnected from the data logger and recovered in summer 2009, but the handle to the brass electrical connector attached to the top of the old data logger broke off when removal was attempted. It appears that the connector is corroded in place on top of the wellhead. This was confirmed with a subsequent visit with the ROPOS in October 2010, when an attempt was made to rotate and pry the connector free. After $20 \mathrm{~min}$ of vigorous lifting, hammering, and rotation, the brass connector remained firmly fixed to the steel logger body, but the logger appeared to rotate within the CORK body. The old data logger may still be collecting pressure data, but accessing these data will require removal of the brass connector. Researchers are planning during summer 2011 ROV operations to remove the connector and old logger from the wellhead and install an adapter and pass-through fitting that allows use of a modern pressure logging system. There are no fluid or microbiology sampling systems installed on or below this CORK wellhead.

\section{Plans for ongoing and future experiments}

Planning is under way for summer 2011 and 2012 dive operations (with the ROV Jason operated from the Atlantis) to service all of the CORK systems discussed above and to conduct additional sampling and experimental operations. CORKs installed before Expedition 327 were monitoring during Expedition 327 operations, including a $24 \mathrm{~h}$ pumping and tracer injection experiment, and data and samples collected in summer 2011 will be examined for evidence of cross-hole and vertical hydrogeologic communication.

In addition, the dust-cap will be removed from the large-diameter ball valve on the wellhead of the CORK in Hole U1362B, an autonomous flowmeter will be installed, and the ball valve will be opened. This CORK system, which is installed where basement fluids are known to be overpressured, will be allowed to flow freely for at least $1 \mathrm{y}$, providing a long-term perturbation for pressure conditions in basement in surrounding CORK systems and permitting access to a large volume of borehole and formation fluid over time. The ball valve will be closed in summer 2012, allowing recovery after a year of discharge of warm, altered formation fluids. This will result in another pressure response in surrounding holes, comprising an additional large-scale experiment. The flow experiment could be extended by installing the flowmeter on the ball valve on the CORK wellhead in Hole U1362A and allowing fluids from this location to flow freely, providing access to additional formation material from a greater depth in the crust.

Wellhead OsmoSampler systems will be deployed and replaced as needed in 2011 and 2012, respectively, but recovery and analysis of downhole temperature loggers, fluid samplers, and microbial experimental systems will most likely occur during subsequent CORK visits, as these systems were designed for deployment of 5-6 y. Samples from these systems will allow researchers to assess the return of conditions at depth below the CORKs to a predrilling state and to determine if there is evidence for arrival of one or more of the tracers injected during Expedition 327.

\section{Acknowledgments}

We thank many colleagues working with Transocean and the US Implementing Organization of IODP for their dedicated work in preparing for Expedition 327 . We are particularly appreciative of the skill, perseverance, and creative problem solving provided by Joe (Bubba) Attryde and Phil Christie (core technicians and tools pushers), Mike Storms and Steve Midgley (operations superintendents), Wayne Malone (operations manager), and Nick Parrish and Charlie Watts (drillers). Cementing of casing systems was ably managed by Cecil (Jardin) Jones. The shipboard technical group led by Bill Mills (laboratory officer) and Lisa Crowder and Tim Bronk (assistant laboratory officers) provided critical technical support during CORK preparation and deployment operations. We also thank the IODP scientific advisory structure and community at large for giving us the opportunity to push engineering, operational, logistical, technical, and scientific envelopes through these experiments.

CORK servicing has been ably supported by the crew, technicians, and officers of the R/V Atlantis and R/V Thomas G. Thompson and the skilled pilots of Alvin, Jason, and ROPOS. These experiments were supported by US National Science Foundation grants OCE-0550713 and OCE-0727952 (ATF), OCE0549955 and OCE-0727119 (CGW), OCE-0550202 and OCE-0726887 (KB), and MCB-0604014 and OCE-0726838 (JPC). Additional support was provided by the NASA Astrobiology Institute cooperative agreement NNA09DA77A (JPC) and a grant from the Gordon and Betty Moore Foundation (KJE and 
CGW). This is contribution number 101 from the Center for Dark Energy Biosphere Investigations.

\section{References}

Becker, K., and Davis, E.E., 2005. A review of CORK designs and operations during the Ocean Drilling Program. In Fisher, A.T., Urabe, T., Klaus, A., and the Expedition 301 Scientists, Proc. IODP, 301: College Station, TX (Integrated Ocean Drilling Program Management International, Inc.). doi:10.2204/iodp.proc.301.104.2005

Boschker, H.T.S., Nold, S.C., Wellsbury, P., Bos, D., de Graaf, W., Pel, R., Parkes, R.J., and Cappenberg, T.E., 1998. Direct linking of microbial populations to specific biogeochemical processes by ${ }^{13} \mathrm{C}$-labeling of biomarkers. Nature (London, U. K.), 392(6678):801-805. doi:10.1038/33900

Davis, E.E., and Becker, K., 2002. Observations of naturalstate fluid pressures and temperatures in young oceanic crust and inferences regarding hydrothermal circulation. Earth. Planet. Sci. Lett., 204(1-2):231-248. doi:10.1016/S0012-821X(02)00982-2

Davis, E.E., and Becker, K., 2004. Observations of temperature and pressure: constraints on ocean crustal hydrologic state, properties, and flow. In Davis, E.E., and Elderfield, H. (Eds.), Hydrogeology of the Oceanic Lithosphere: Cambridge (Cambridge Univ. Press), 225-271.

Davis, E.E., Becker, K., Pettigrew, T., Carson, B., and MacDonald, R., 1992a. CORK: a hydrologic seal and downhole observatory for deep-ocean boreholes. In Davis, E.E., Mottl, M.J., Fisher, A.T., et al., Proc. ODP, Init. Repts., 139: College Station, TX (Ocean Drilling Program), 43-53. doi:10.2973/odp.proc.ir.139.103.1992

Davis, E.E., Chapman, D.S., Mottl, M.J., Bentkowski, W.J., Dadey, K., Forster, C., Harris, R., Nagihara, S., Rohr, K., Wheat, G., and Whiticar, M., 1992b. FlankFlux: an experiment to study the nature of hydrothermal circulation in young oceanic crust. Can. J. Earth Sci., 29(5):925-952.

Davis, E.E., Fisher, A.T., Firth, J.V., et al., 1997. Proc. ODP, Init. Repts., 168: College Station, TX (Ocean Drilling Program). doi:10.2973/odp.proc.ir.168.1997

Davis, E.E., LaBonte, A., He, J., Becker, K., and Fisher, A., 2010. Thermally stimulated "runaway" downhole flow in a superhydrostatic ocean crustal borehole: observations, simulations, and inferences regarding crustal permeability. J. Geophys. Res., [Solid Earth], 115(B7):B07102. doi:10.1029/2009JB006986

Edwards, K.J., McCollom, T.M., Konishi, H., and Buseck, P.R., 2003. Seafloor bioalteration of sulfide minerals: results from in situ incubation studies. Geochim. Cosmochim. Acta, 67(15):2843-2856. doi:10.1016/S00167037(03)00089-9

Expedition 301 Scientists, 2005a. Site 1026. In Fisher, A.T., Urabe, T., Klaus, A., and the Expedition 301 Scientists, Proc. IODP, 301: College Station, TX (Integrated Ocean Drilling Program Management International, Inc.). doi:10.2204/iodp.proc.301.107.2005
Expedition 301 Scientists, 2005b. Site U1301. In Fisher, A.T., Urabe, T., Klaus, A., and the Expedition 301 Scientists, Proc. IODP, 301: College Station, TX (Integrated Ocean Drilling Program Management International, Inc.). doi:10.2204/iodp.proc.301.106.2005

Fisher, A.T., Becker, K., and Davis, E.E., 1997. The permeability of young oceanic crust east of Juan de Fuca Ridge determined using borehole thermal measurements. Geophys. Res. Lett., 24(11):1311-1314. doi:10.1029/ 97GL01286

Fisher, A.T., Davis, E.E., and Becker, K., 2008. Borehole-toborehole hydrologic response across $2.4 \mathrm{~km}$ in the upper oceanic crust: implications for crustal-scale properties. J. Geophys. Res., [Solid Earth], 113(B7):B07106. doi:10.1029/2007JB005447

Fisher, A.T., and IODP Expedition 321T Scientific Party, 2010. IODP Expedition 321T: cementing operations at Holes U1301A and U1301B, eastern flank of the Juan de Fuca Ridge. Sci. Drill., 9:16-19. doi:10.2204/ iodp.sd.9.02.2010

Fisher, A.T., Wheat, C.G., Becker, K., Davis, E.E., Jannasch, H., Schroeder, D., Dixon, R., Pettigrew, T.L., Meldrum, R., McDonald, R., Nielsen, M., Fisk, M., Cowen, J., Bach, W., and Edwards, K., 2005. Scientific and technical design and deployment of long-term subseafloor observatories for hydrogeologic and related experiments, IODP Expedition 301, eastern flank of Juan de Fuca Ridge. In Fisher, A.T., Urabe, T., Klaus, A., and the Expedition 301 Scientists, Proc. IODP, 301: College Station, TX (Integrated Ocean Drilling Program Management International, Inc.). doi:10.2204/ iodp.proc.301.103.2005

Ginige, M.P., Hugenholtz, P., Daims, H., Wagner, M., Keller, J., and Blackall, L.L., 2004. Use of stable-isotope probing, full-cycle rRNA analysis, and fluorescence in situ hybridization-microautoradiography to study a methanol-fed denitrifying microbial community. Appl. Environ. Microbiol., 70(1):588-596. doi:10.1128/ AEM.70.1.588-596.2004

Jannasch, H.W., Wheat, C.G., Plant, J.N., Kastner, M., and Stakes, D.S., 2004. Continuous chemical monitoring with osmotically pumped water samplers: OsmoSampler design and applications. Limnol. Oceanogr.: Methods, 2:102-113. http://aslo.org/lomethods/free/2004/ 0102.pdf

Orcutt, B.N., Bach, W., Becker, K., Fisher, A.T., Hentscher, M., Toner, B.M., Wheat, C.G., and Edwards, K.J., 2011. Colonization of subsurface microbial observatories deployed in young ocean crust. ISME J., 5(4):692-703. doi:10.1038/ismej.2010.157

Orcutt, B., Wheat, C.G., and Edwards, K.J., 2010. Subseafloor ocean crust microbial observatories: development of FLOCS (FLow-through Osmo Colonization System) and evaluation of borehole construction materials. Geomicrobiol. J., 27(2):143-157. doi:10.1080/ 01490450903456772

Orphan, V.J., House, C.H., Hinrichs, K.-U., McKeegan, K.D., and DeLong, E.F., 2001. Methane-consuming archaea revealed by directly coupled isotopic and phy- 
logenetic analysis. Science, 293(5529):484-487. doi:10.1126/science.1061338

Radajewski, S., Ineson, P., Parekh, N.R., and Murrell, J.C., 2000. Stable-isotope probing as a tool in microbial ecology. Nature (London, U. K.), 403(6770):646-649. doi:10.1038/35001054

Ryan, W.B.F., Carbotte, S.M., Coplan, J.O., O'Hara, S., Melkonian, A., Arko, R., Weissel, R.A., Ferrini, V., Goodwillie, A., Nitsche, F., Bonczkowski, J., and Zemsky, R., 2009. Global multi-resolution topography synthesis. Geochem., Geophys., Geosyst., 10(3):Q03014. doi:10.1029/2008GC002332

Shipboard Scientific Party, 1997. Rough basement transect (Sites 1026 and 1027). In Davis, E.E., Fisher, A.T., Firth, J.V., et al., Proc. ODP, Init. Repts., 168: College Station, TX (Ocean Drilling Program), 101-160. doi:10.2973/ odp.proc.ir.168.105.1997

Smith, A., Popa, R., Fisk, M., Nielsen, M., Wheat, C.G., Jannasch, H., Fisher, A.T., Becker, K., Sievert, S., and Flores, G., submitted. A novel method for studying in situ microbial colonization of igneous minerals and glasses in ocean crust. Geochem., Geophys., Geosyst.

Wheat, C.G., Jannasch, H.W., Fisher, A.T., Becker, K., Sharkey, J., and Hulme, S., 2010. Subseafloor seawater- basalt-microbe reactions: continuous sampling of borehole fluids in a ridge flank environment. Geochem., Geophys., Geosyst., 11(7):Q07011. doi:10.1029/ 2010GC003057

Wheat, C.G., and Mottl, M.J., 2000. Composition of pore and spring waters from Baby Bare: global implications of geochemical fluxes from a ridge flank hydrothermal system. Geochim. Cosmochim. Acta, 64(4):629-642. doi:10.1016/S0016-7037(99)00347-6

Zühlsdorff, L., Hutnak, M., Fisher, A.T., Spiess, V., Davis, E.E., Nedimovic, M., Carbotte, S., Villinger, H., and Becker, K., 2005. Site surveys related to IODP Expedition 301: ImageFlux (SO149) and RetroFlux (TN116) expeditions and earlier studies. In Fisher, A.T., Urabe, T., Klaus, A., and the Expedition 301 Scientists, Proc. IODP, 301: College Station, TX (Integrated Ocean Drilling Program Management International, Inc.). doi:10.2204/ iodp.proc.301.102.2005

Initial receipt: 4 November 2010

Acceptance: 31 March 2011

Publication: 5 September 2011

MS 327-107 
Figure F1. Maps showing locations of CORK observatories discussed in this paper. A. Regional map showing location of Ocean Drilling Program (ODP) Leg 168 transect and Integrated Ocean Drilling Program (IODP) Expedition 301 and 327 work areas. Yellow rectangle indicates area of Figure F1B. Regional map generated using GeoMapApp (www.geomapapp.org/) and the global multiresolution topography synthesis (Ryan et al., 2009). B. Site map showing locations of ODP/IODP Holes 1026B, 1027C, U1301A, U1301B, U1362A, and U1362B (see the "Site U1362" chapter; Expedition 301 Scientists, 2005b; Shipboard Scientific Party, 1997). Gold contours show locations of basement outcrops (Davis et al., 1992b; Zühlsdorff et al., 2005). Sites 1026, U1301, and U1362 are aligned above a buried basement high, where sediment thickness is 236-265 m, whereas Site 1027 is located above an area of thicker sediment and deeper basement.
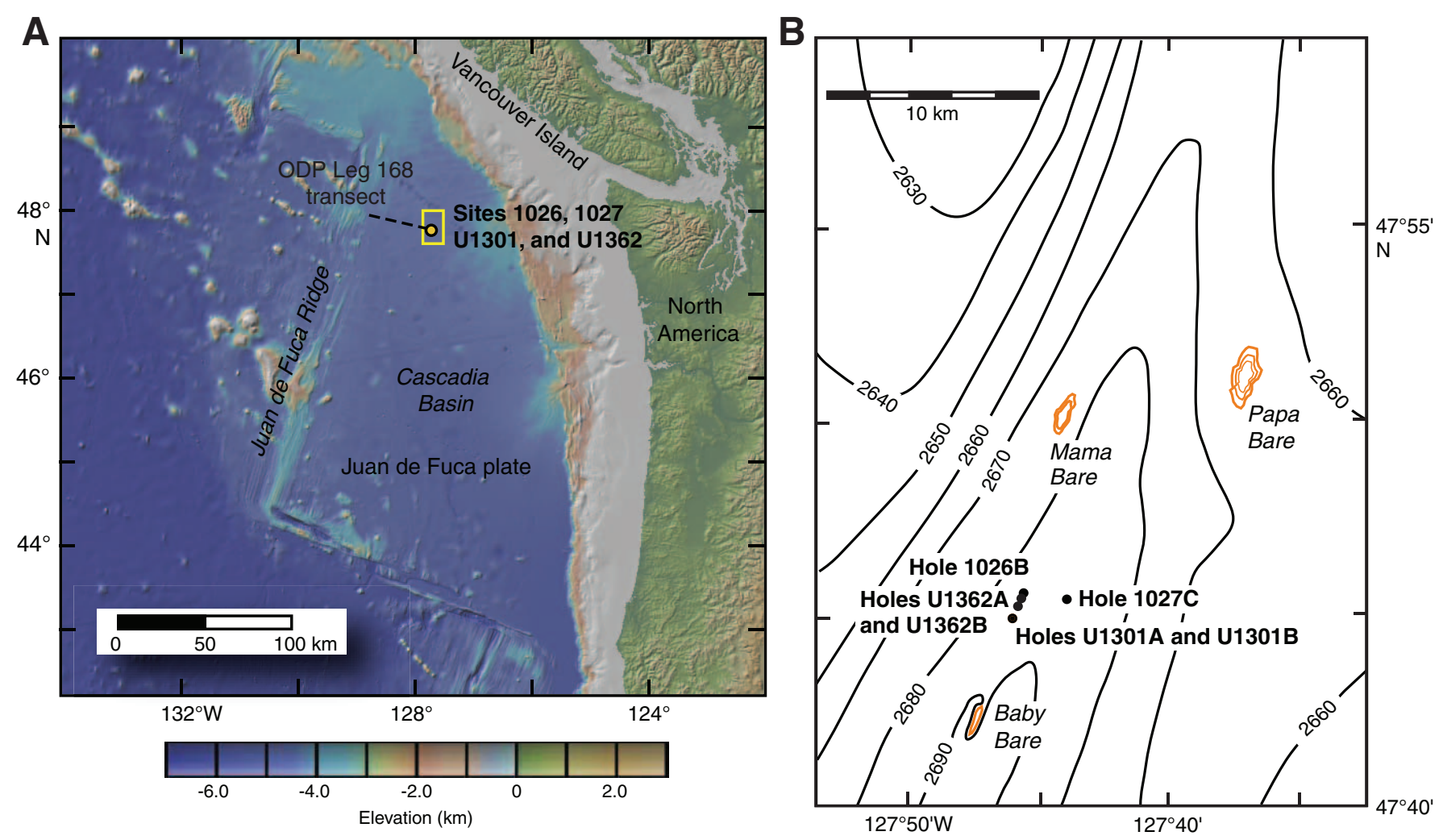
Figure F2. Cartoon showing features of new CORK systems deployed during Expedition 327. Characteristics of Expedition 327 CORKs that differ from earlier generations of borehole observatories include perforated and coated drill collars and casing at depth, two kinds of CORK and casing packers (inflatable and swellable), a casing seal between 103/4 inch and 16 inch casing strings, a tapered gravity plug for a top seal, and a free-flow valve in the L-CORK wellhead. Additional features that Expedition 327 CORKs have in common with the last generation of CORKs deployed during Expedition 301 include main CORK seal in the throat of the reentry cone within 103/4 inch casing; primary CORK casing diameter of $4 \frac{1}{2}$ inches; up to eight fluid, microbiological, and pressure sampling lines, with ports and screens at various depths; and a mixture of fluid and microbiological sampling systems suspended on Spectra cable at depth. Temperatures are recorded with autonomous sensor and logging instruments incorporated into the fluid and microbiological samplers or hung independently from the Spectra cable. Specific configurations for each Expedition 327 CORK are shown in later figures and tables and discussed in the text.

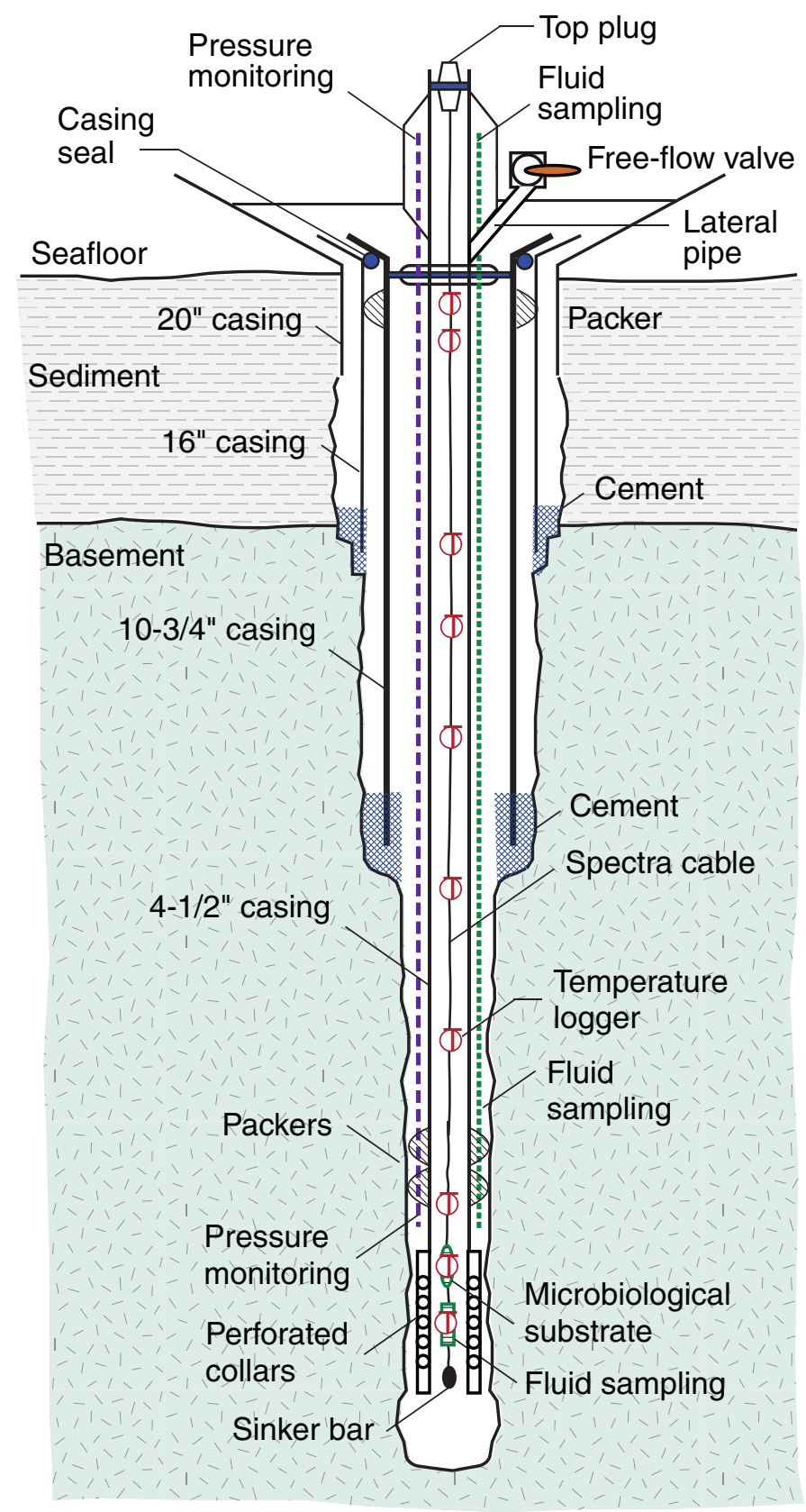


Figure F3. Photographs of Expedition 327 subseafloor borehole observatory ("CORK") wellheads. A. Three CORK wellheads secured to the top of the core technician shop, aft of the rig floor, near the start of Expedition 327. The tops of the CORK wellheads are shown at the bottom of the photograph, and the first short sections of $4 \frac{1}{2}$ inch CORK casing are visible at the top of the photograph, extending beyond the roof of the core tech shop. The center and rightmost CORKs were deployed in Holes U1362A and U1362B, respectively, whereas the leftmost CORK was prepared for Hole 1027C but could not be deployed during Expedition 327. The hole at the top of each CORK wellhead (bottom of the photograph) receives an instrument string and plug. Instrument and sampling bays are visible near the center of the wellheads, with valves and fittings covered by white plastic bags to protect them from grit and grease prior to installation. These bags were removed immediately before each CORK was deployed through the moonpool. Ball valves to be used for the free-flow experiment are visible near the bottom of the visible bays on the Hole U1362A and U1362B CORKs (black with yellow handles). B. Hole U1362A CORK being hoisted onto the rig floor using the draw works and CORK running tool. Instruments visible on the right side of the wellhead are a pressure logger and gauges.
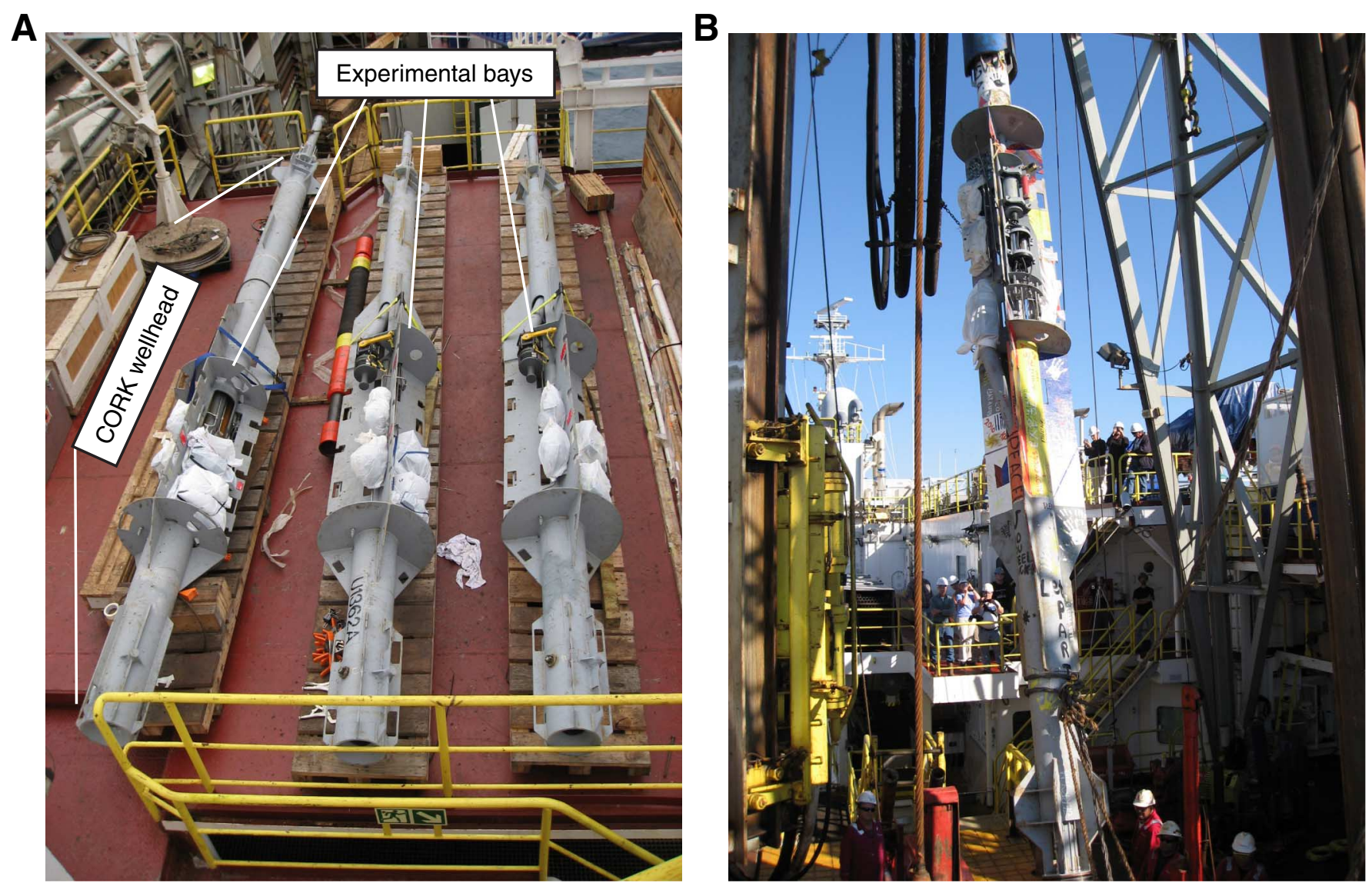
Figure F4. Photographs of subseafloor borehole observatory (CORK) seal systems and components used during Expedition 327. A. Casing seal subs attached to $10^{3 / 4}$ inch casing hangers. Sealing is accomplished with a combination of metal-on-metal and O-ring contact between the $103 / 4$ and 16 inch casing hangers. B. Swellable casing packer installed near the top of the 103/4 inch casing strings in Holes U1362A and U1362B. The rubber element is composed of a material that reacts and expands in the presence of seawater, helping to fill the annular gap between the packer element and the 16 inch casing. C. CORK seal at the base of the Hole U1362A wellhead. The seal is formed by two polypacks, U-shaped plastic pieces that surround an O-ring. Note sampling and monitoring tubes that pass through the CORK seal, connecting wellhead instruments and valves above to the formation intervals at depth. D. Inflatable packer element with $8 \frac{1}{2} 2$ inch outside diameter, installed at depth inside casing and open hole. Inflatable packers were deployed in tandem with swellable packer elements, helping to isolate open basement intervals. E. Swellable casing packer installed on $4 \frac{1}{2} 2$ inch CORK casing. Tubing umbilicals pass through the packer using slots premilled into the element housing. This particular element was turned down on a lathe to make the diameter small enough to permit deployment in the open hole. These swellable casing packers are deployed in pairs. F. Lower end of top plug for Hole U1362A CORK. The top plug is sealed by an O-ring held in position against a tapered seal area by the weight of the plug, instrument string, and sinker bar.
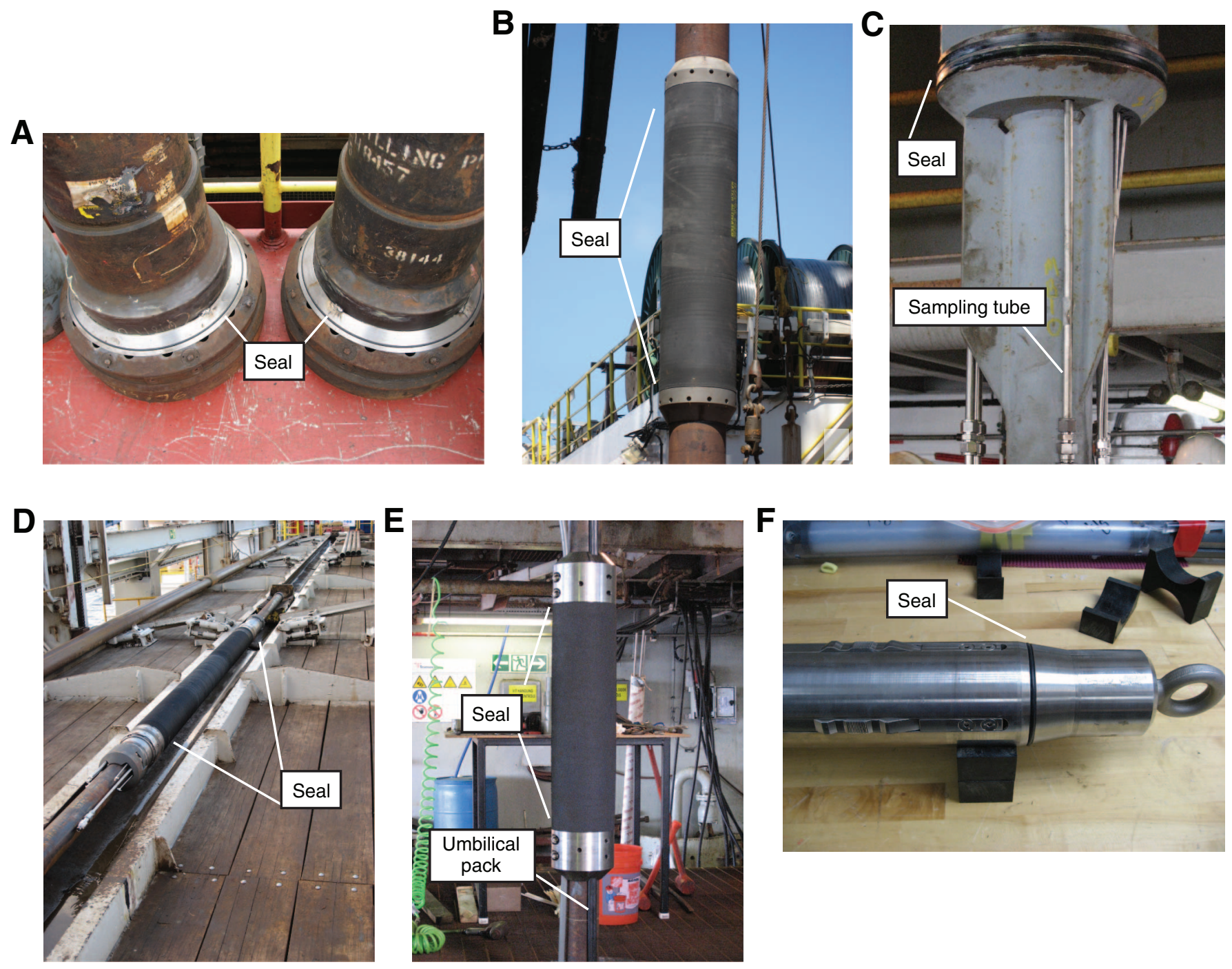
Figure F5. Photographs of perforated and screened components permitting monitoring and sampling from isolated intervals at depth below the seafloor, Expedition 327. A. Perforated drill collar being made up to a bullnose at the end of a CORK casing string. Collar and bullnose were coated internally and externally with epoxy compounds intended to reduce reactivity with warm formation fluids and seawater. B. Close-up of perforated drill collar running into the moonpool, with lines of 2 inch holes separated by 9 inches. C. Perforated and coated 51/2 inch casing being cleaned with alcohol prior to deployment. Lines of $1 \frac{1 / 2}{2}$ inch perforations are separated by 8 inches. D. Pressure miniscreen (stainless steel, wire wrap, $1 \mathrm{~m} \mathrm{long}$ ) made up to the outside of the $4 \frac{1}{2}$ inch casing immediately below an inflatable casing packer. E. Geochemical sampling miniscreens (stainless steel, wire wrap, $1 \mathrm{~m}$ long) made up on the outside of perforated and coated 51/2 inch casing located below inflatable packer element and above drill collars. F. Microbiology miniscreen (titanium, wire wrap, $1 \mathrm{~m}$ long) being attached to the outside of perforated and coated 51/2 inch casing, just above the drill collars.
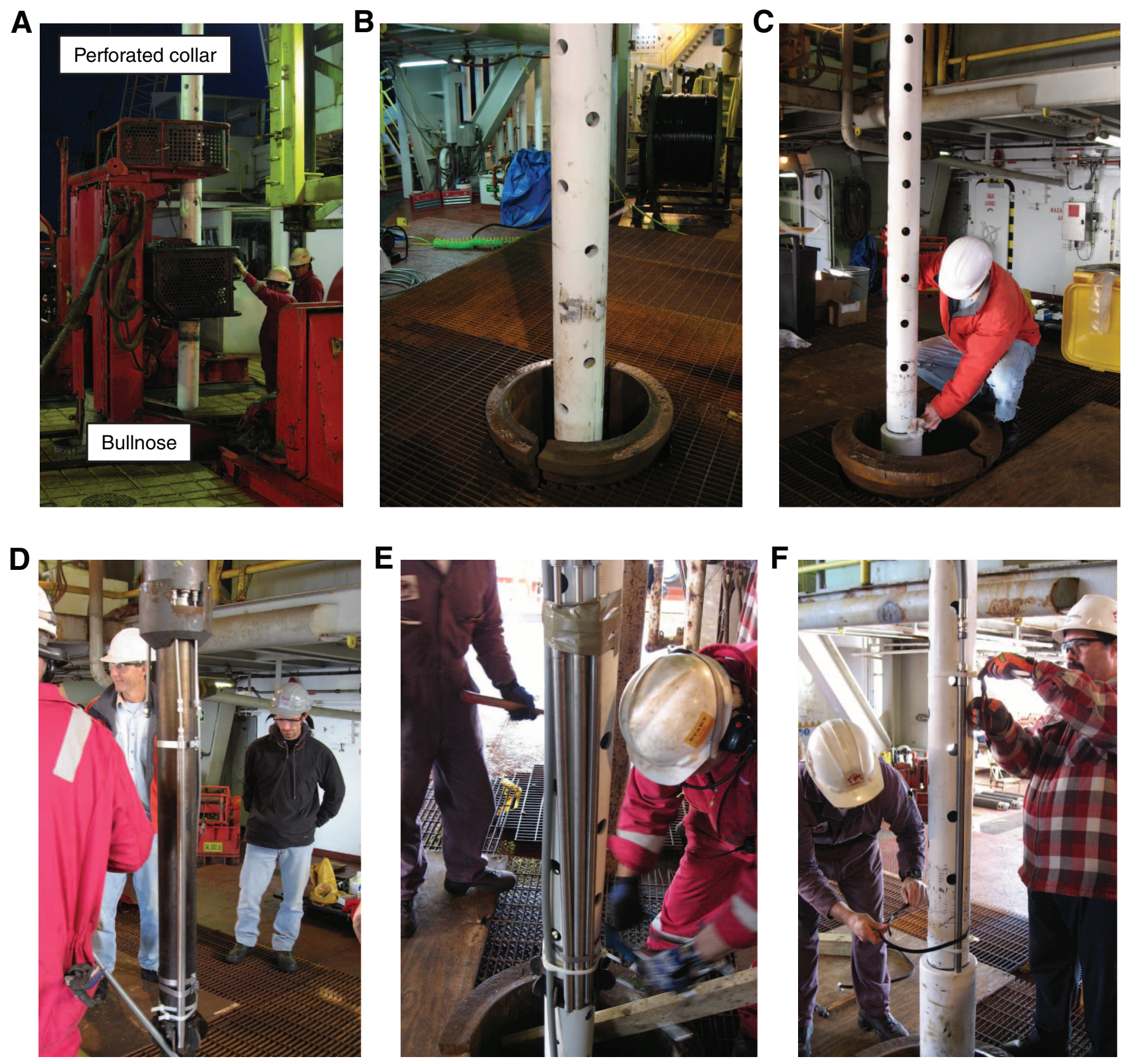
Figure F6. Photographs of Expedition 327 CORK umbilical bundles and tubing. A. Black umbilical flat pack containing one packer inflation line ( $1 / 2$ inch) and two pressure monitoring lines $(1 / 4 \mathrm{inch})$, both stainless steel. B. Black umbilical flat pack containing three stainless steel geochemical sampling lines (all $1 / 2$ inch). C. Microbiological sampling line ( $1 / 2$ inch) made from inner PTFE tubing, braided steel jacket, and hard plastic outer shell. D. Inflatable packer elements were preconfigured with tubing pass-throughs for up to eight lines: packer inflation, fluid sampling (3), pressure monitoring (2), and microbiological sampling. E. Swellable packer elements were premachined to pass tubing umbilicals with slots that were premilled into the element housing. The casing below the elements was wrapped in the same swellable compound so that the elements would seal against the umbilical tubing from both sides once the material had a chance to react with seawater. F. Centralizers were placed on the CORK tubing to help protect the tubing connections from damage against the throat of the reentry cone or borehole wall during reentry. Pieces of the microbiological sampling line were used as flexible pigtail connections in Hole U1362B.
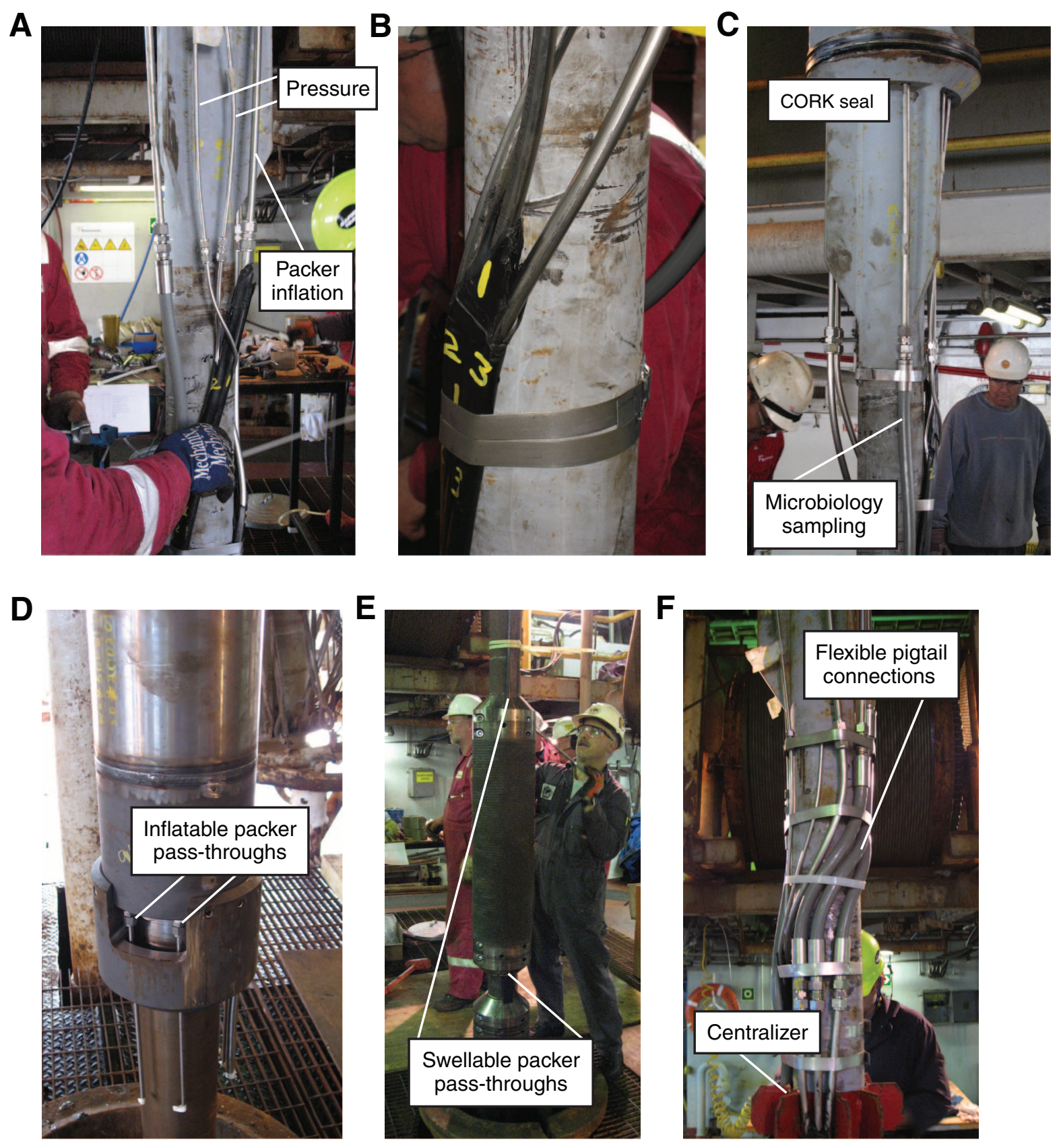
Figure F7. Photographs of large-diameter ball-valve system developed for Expedition 327 CORKs to permit long-term free-flow experiment. A. Ball-valve system prepared on deck for deployment. Ball valve (Banjo V400, polypropylene) has 4 inch internal diameter and is open when handle is rotated $90^{\circ}$ counterclockwise from position shown. Instrument clamp mounted above ball valve currently contains a dust cover, but this will be replaced with an autonomous flowmeter system using a remotely operated vehicle (ROV). B. Side view showing cut-away section of CORK bulkhead, providing clearance for rotation of ball-valve handle. Lateral pipe that extends outward from the main $4 \frac{1}{2}$ inch CORK casing allows fluids from deep below the wellhead to flow up through the ball valve when it is opened, even though a sealed plug will remain in place at the top of the wellhead. C. View of the instrument clamp with the dust cover removed and the clamp open. Clamp is actuated by pulling the latch toward you to open (counterclockwise when viewed from above) and pushing the latch away to close (clockwise when viewed from above). Moving latch shifts dogs that engage the dust cover, flowmeter, or other instrument designed to fit into the clamp. D. Ball valve just before CORK deployment. Yellow rope loops will assist submersible or ROV manipulator to grasp ball-valve handle and clamp latch. Loops and dust cover are held in place for deployment with rubber bands.
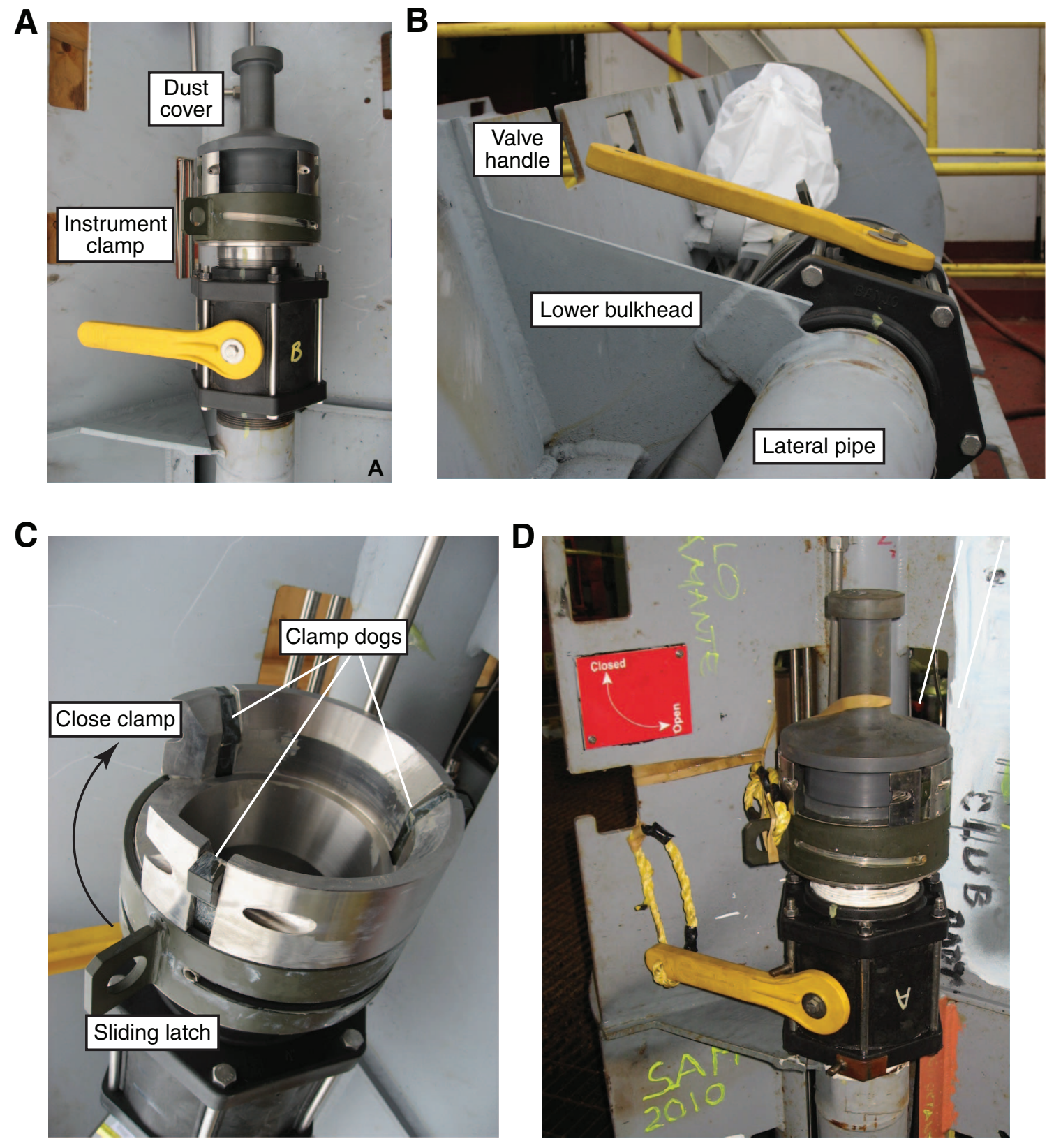
Figure F8. Photographs of pressure logging systems. A. Three sets of CORK pressure logging systems prepared for Expedition 327. Electronics components are built into frames that are subsequently attached in one of three CORK wellhead bays. Pressure logging systems comprise (right to lift in photograph; top to bottom when deployed): underwater mateable connector (Teledyne ODI, covered with cap in photograph), pressure case containing electronics and batteries, underwater connectors and cables, and pressure gauges (Paroscientific). B. Pressure gauges are connected with $1 / 16$ inch stainless steel tubes to hydraulic couplers that fit into receptacles attached to the wellhead, located below the pressure logger frame. C. Pressure logger and gauge frame houses pressure case (containing electronics) and underwater mateable connector. Frame slides into rack welded to wellhead, which also aligns hydraulic couplers as they slide into receptacles. D. Pressure lines running from depth reach a high point just below screw-cap air-bleed valves before passing through three-way valves in wellhead. Rotation $180^{\circ}$ counterclockwise opens pressure gauges to monitor seafloor conditions, whereas rotation $180^{\circ}$ clockwise has pressure gauges monitoring conditions within interval at depth below seafloor. Short pieces of stainless steel rod are welded onto valve handles to show which side of valve is open.

A

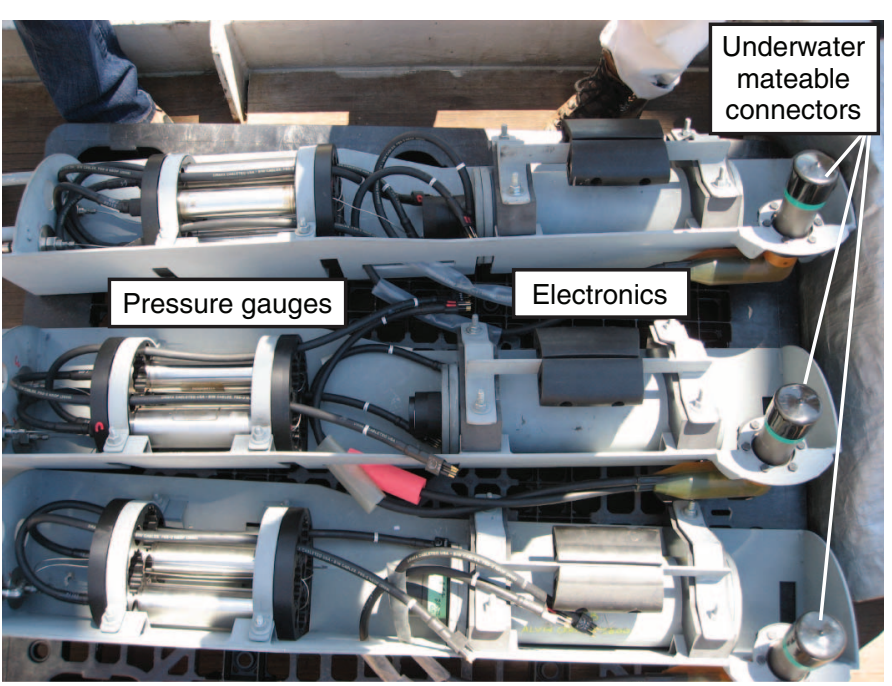

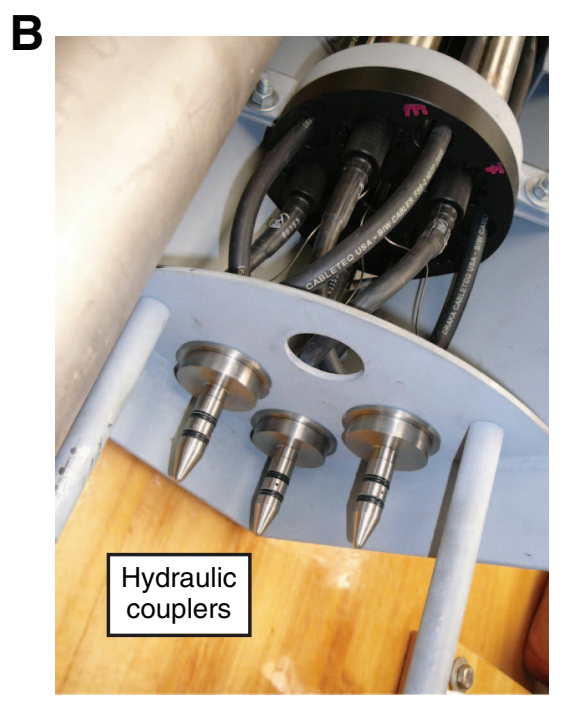

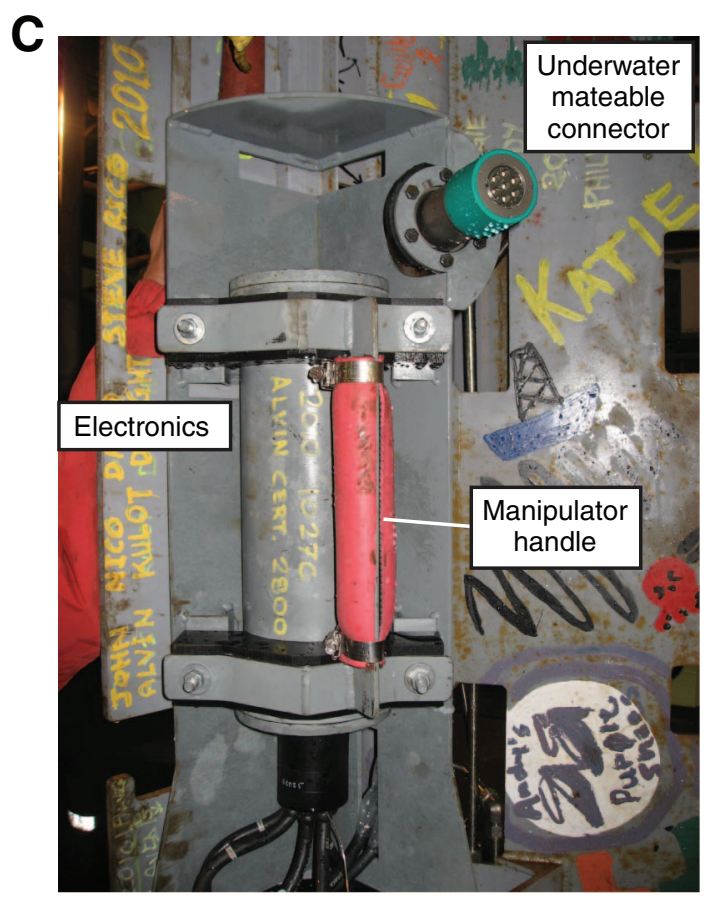

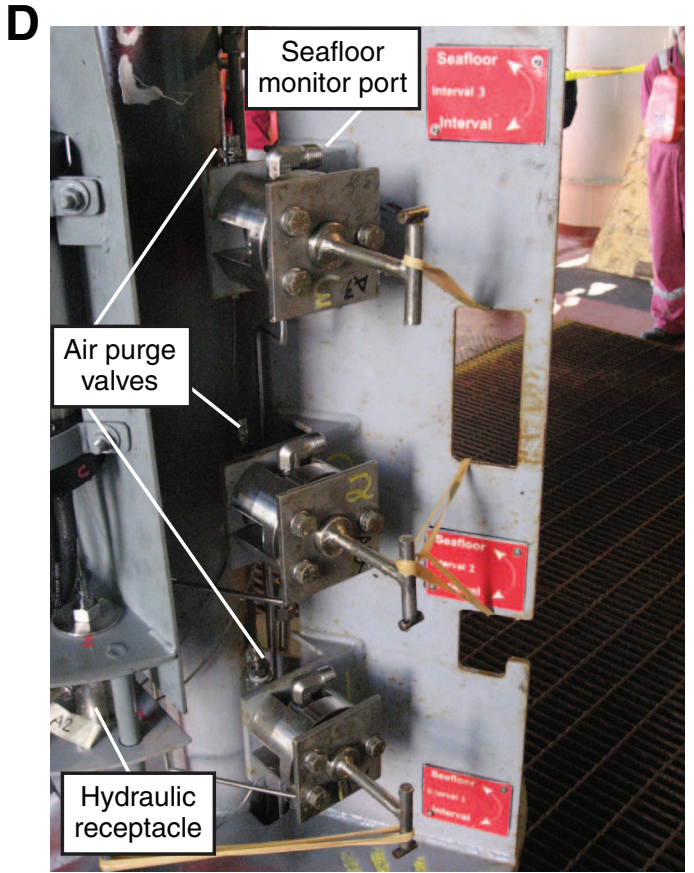


Figure F9. Photographs of temperature logging systems. A. Comparison of three autonomous temperature logger designs. Top: conventional Antares logger, with thermistor in tip on left (time constant of 5-10 s), generally used for short-term deployment (not deployed with CORKs). Middle: "hardened" Antares logger, developed for long-term deployment in subseafloor observatories, with thicker pressure case, double O-ring seal, and additional battery power. Bottom: "hardened" Onset logger, with thermistor located on left side of photograph (time constant of 1-2 min). The latter two kinds of loggers were used on Expedition 327 CORKs. B. Perforated hydraulic hosing being spliced to Spectra cable. Temperature logger is placed inside hosing, which is wrapped in tape, to help protect the logger from damage or loss during deployment and recovery. C. Loggers being deployed on Spectra cable.

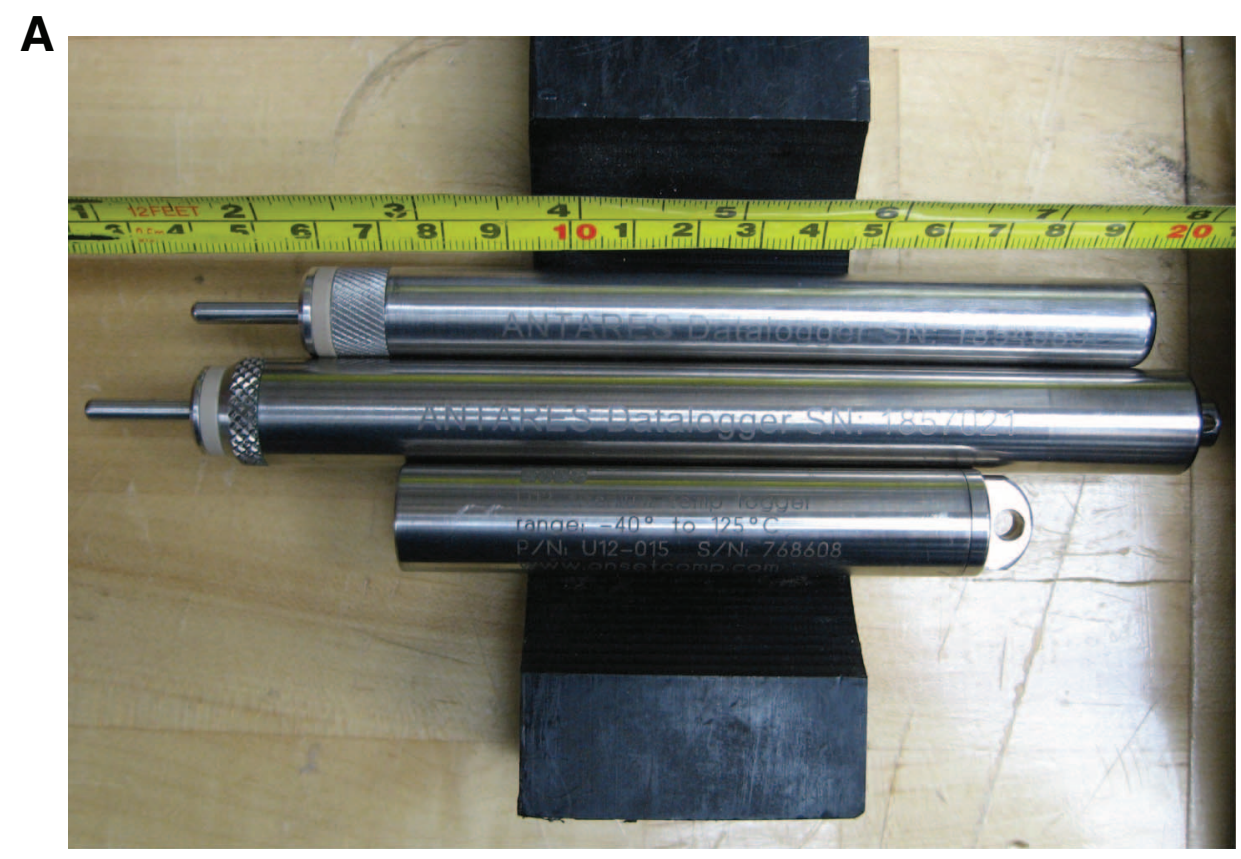

B

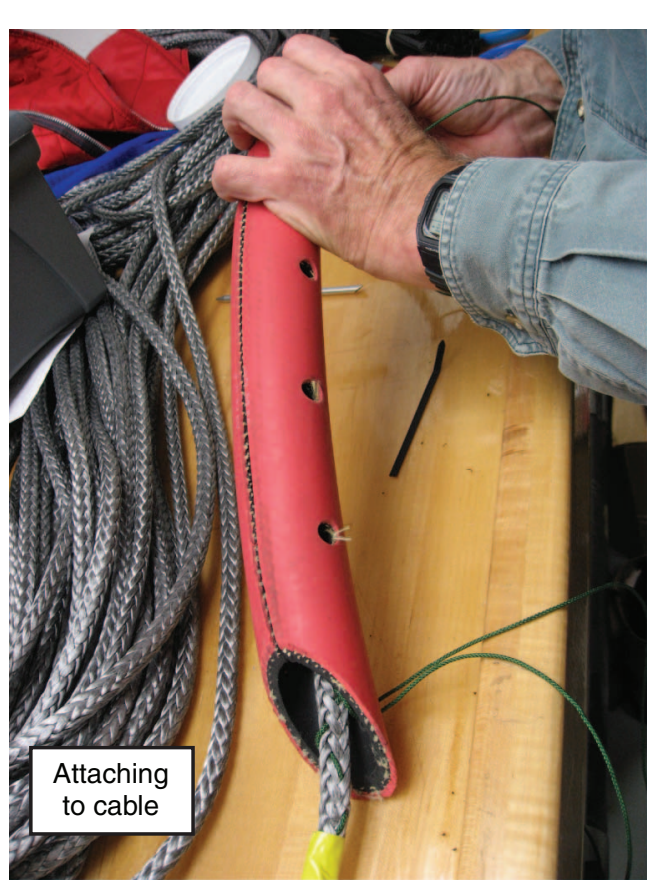

C

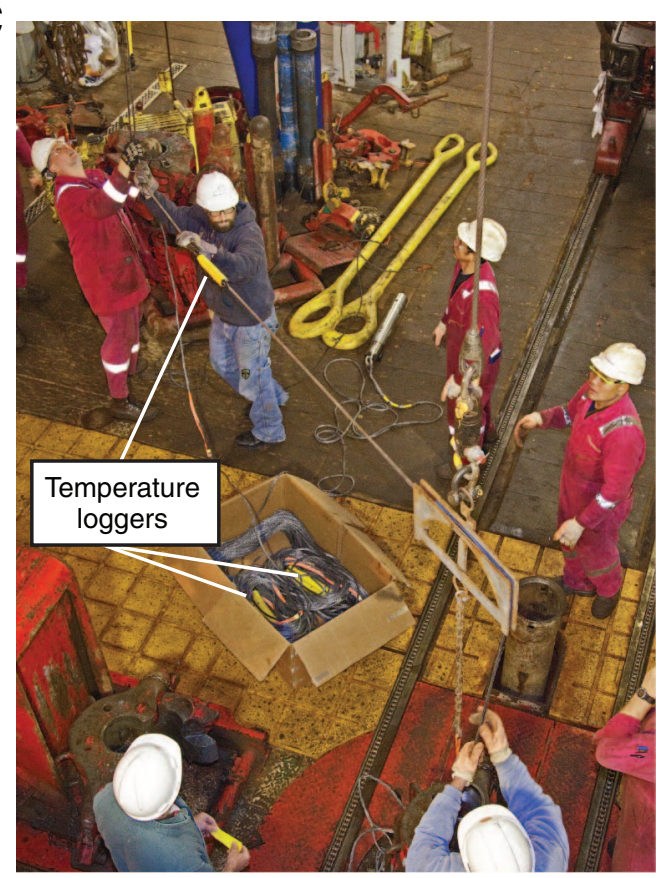


Figure F10. Example plots of typical temperature logger calibration results. For all panels, $x$-axis shows stable calibration bath temperatures, as determined with an NIST-traceable probe, and $y$-axis shows residual temperature errors. A. Calibration for Onset probe. This instrument uses a 12-bit A/D converter and has digital resolution on the order of $0.02^{\circ}-0.1^{\circ} \mathrm{C}$, but repeated measurement at a stable temperature gives greater effective resolution. Calibration in 2009 improved upon factory calibration by removing a systematic offset of $0.04^{\circ}-$ $0.08^{\circ} \mathrm{C}$. B. Calibration of Antares probe purchased in 2004, deployed in an Expedition $301 \mathrm{CORK}$, recovered and refurbished by manufacturer. This probe was recalibrated in 2009, correcting for systematic offset and slope and improving accuracy to $\pm 0.001^{\circ} \mathrm{C}$. Antares probes purchased for CORK deployment in 2004 had a temperature range of $\sim 41^{\circ}-100^{\circ} \mathrm{C}$ and a digital resolution of $0.001^{\circ} \mathrm{C}$. C. Antares tools purchased in 2009 had a full range of $\sim 1^{\circ}-100^{\circ} \mathrm{C}$ and resolution and accuracy on the order of $0.001^{\circ}-0.002^{\circ} \mathrm{C}$. Once again, calibration in 2009 corrected for offset and slope.
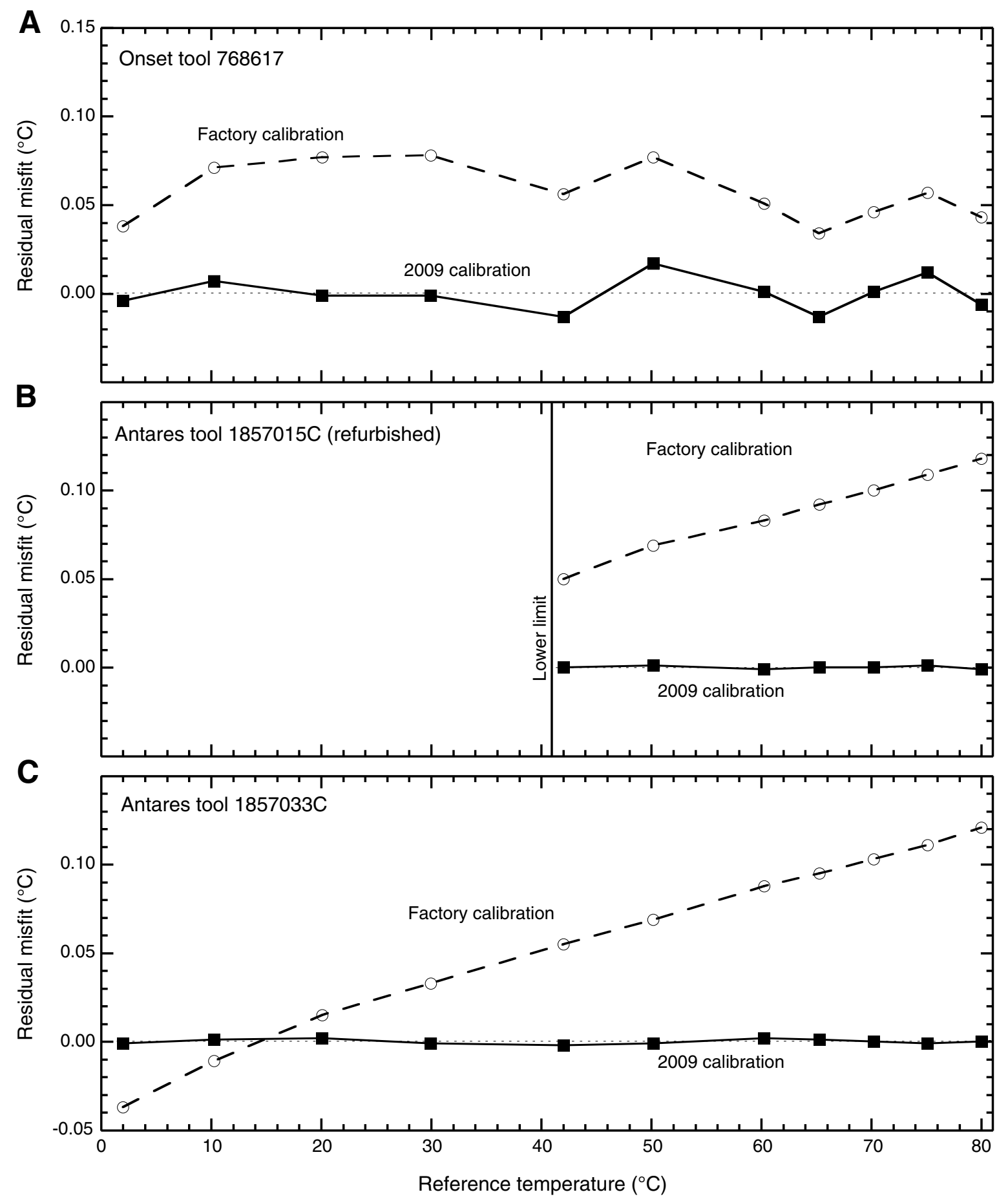
Figure F11. Photographs of downhole OsmoSampler systems. A. OsmoSampler being assembled in laboratory prior to deployment. Several fluid sample coils (PTFE) are being configured in series with a single osmotic pump. Additional OsmoSamplers are visible in the rack below the bench. B. OsmoSampler being deployed on the rig floor. Salt reservoir is visible near top of photograph, with osmotic membrane separating the saturated salt solution from distilled water fluid reservoir in sample coil. C. Two copper tubing sections being deployed as part of a gas-tight OsmoSampler. D. OsmoSampler being deployed on rig floor showing salt reservoir and osmotic membrane at top, PVC holder with temperature logger, and four PTFE sample coils configured in series. The salt reservoir for the next (deeper) OsmoSampler is visible at the bottom of the suspended instrument string.
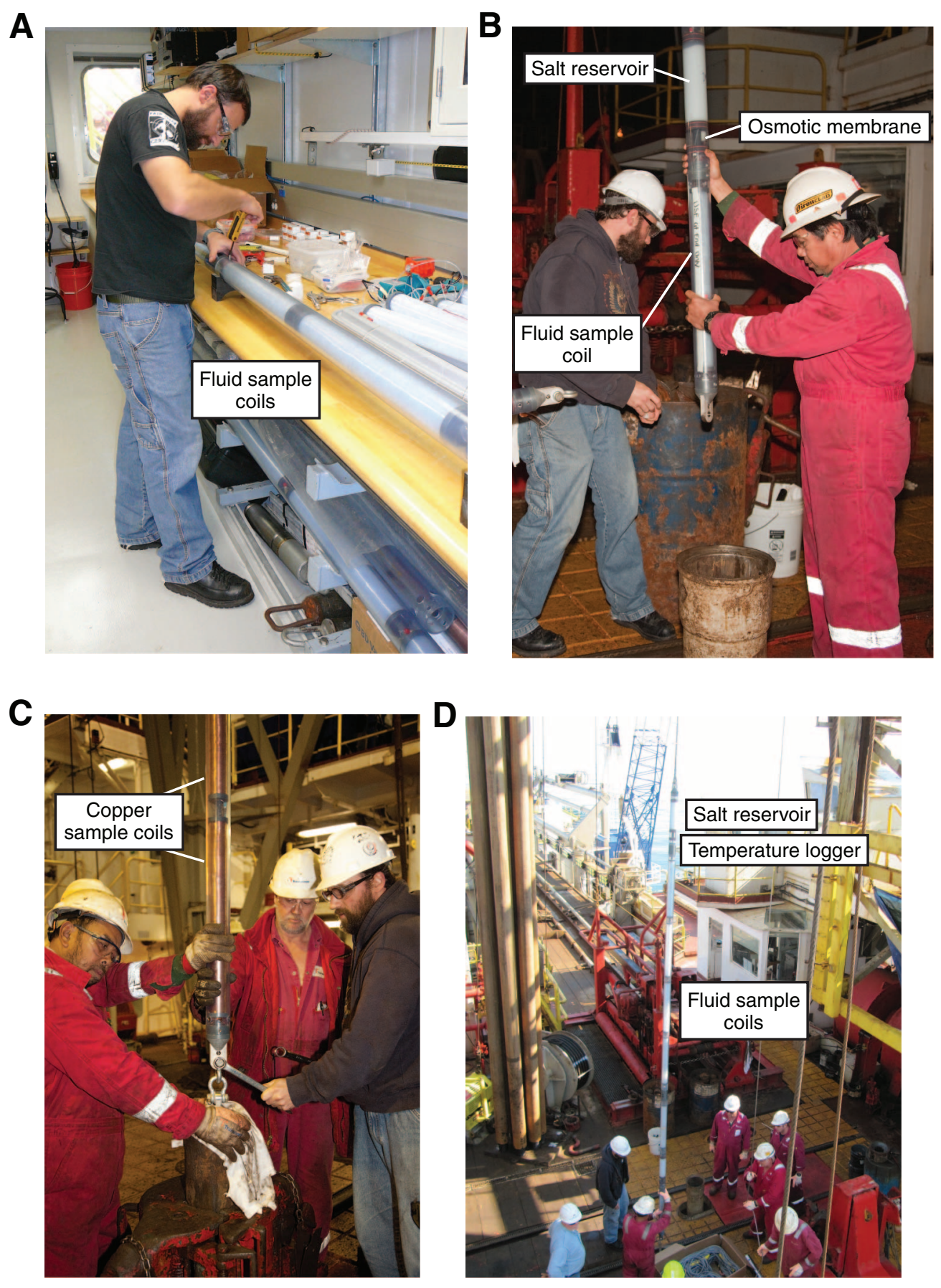
Figure F12. Photographs of microbiological colonization and growth experiments prepared for deployment during Expedition 327. A. Assembled FLOCS colonization experiment for MBIO OsmoSampler package, containing cassettes with a mixture of basalt, sulfide minerals, glass beads, glass wool, and polished mineral chips. B. Assembled FLOCS colonization experiment for enrichment OsmoSampler package. C. FLOCS experiment during deployment of MBIO OsmoSampler package. D. Close-up of polished mineral chips deployed in FLOCS experiments. Mineral chips are, from left to right, glassy basalt from the East Pacific Rise, basalt collected from Hole U1301B during Expedition 327, chalcopyrite, pyrite, pyrrhotite and/or magnetite (last four purchased from Wards Geology). E. FLOCS experiment housed within a modified coupler in enrichment OsmoSampler. Y-union at left connects the FLOCS inflow with the ${ }^{13} \mathrm{C}$-labeled bicarbonate solution, as discussed in text.

A

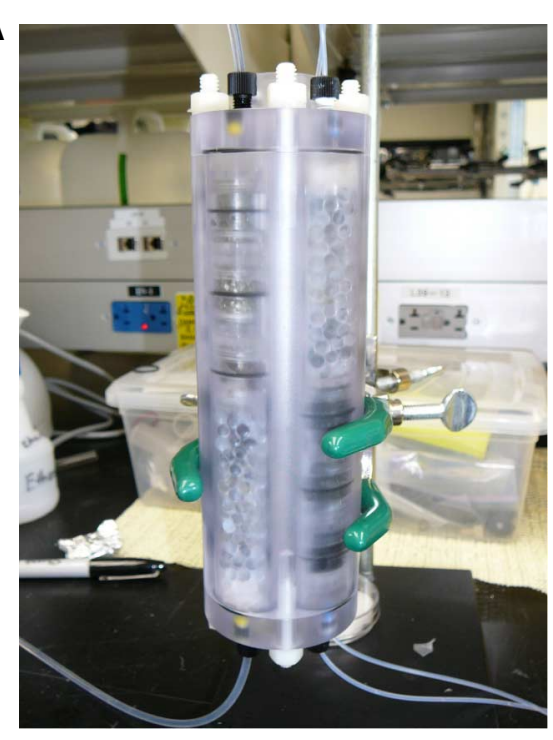

D

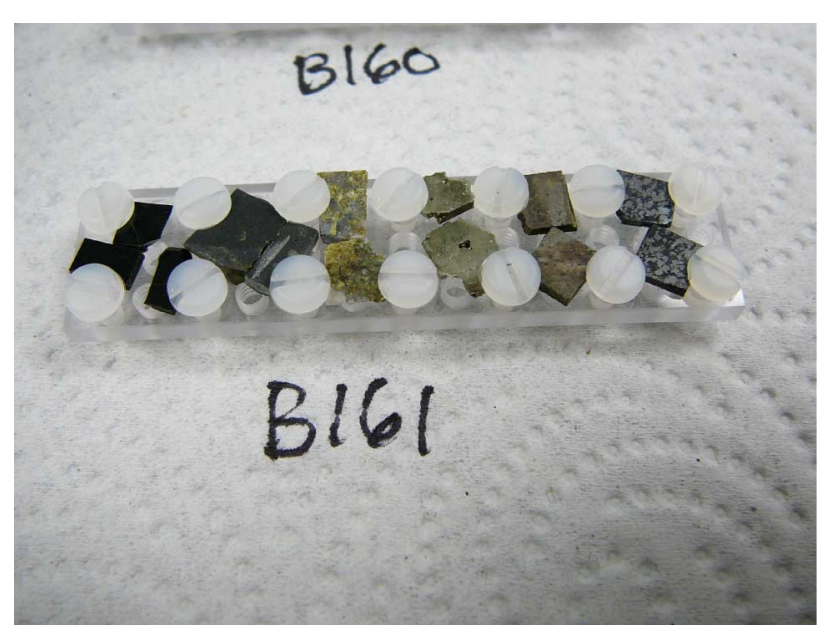

B

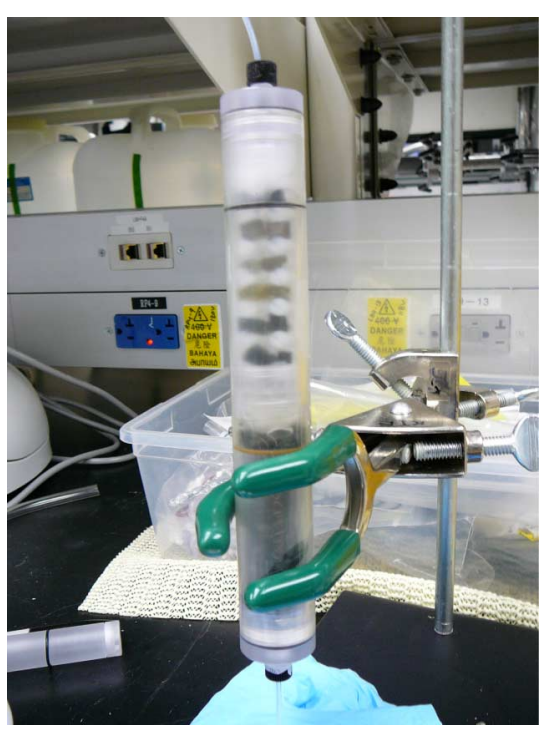

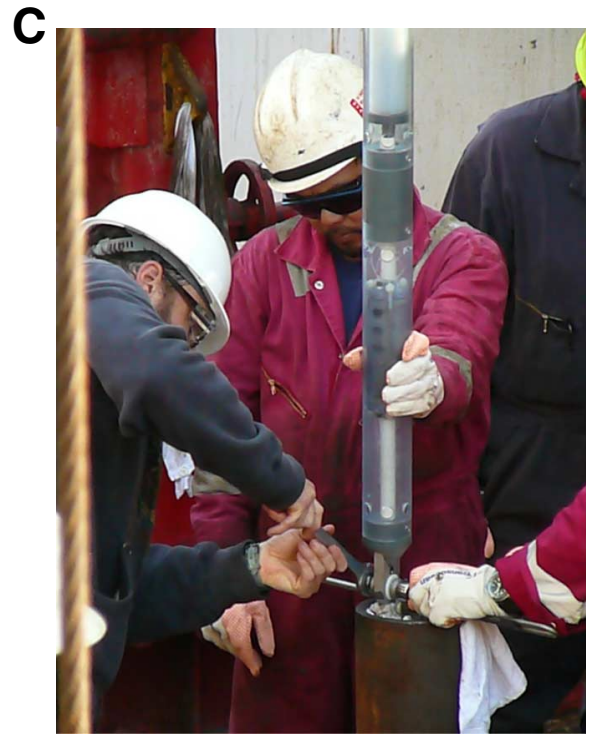

$\mathbf{E}$

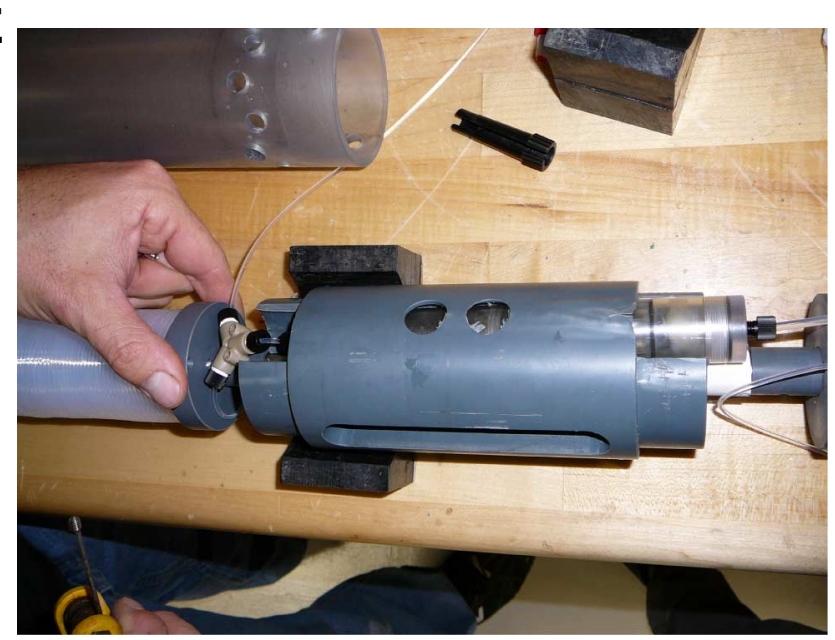


Figure F13. Diagram illustrating layout and distribution of instruments in Hole U1362A CORK. Drawing is to scale vertically but not horizontally, with correct shift between depth below seafloor and depth below top of basement. Hole completion information is summarized in Table T1, and instrumentation and monitoring and sampling depths are listed in Tables T2, T3, T4, and T5. Hole U1362A CORK accesses two distinct monitoring intervals in basement. Engineering drawing of Hole U1362A CORK is shown in Figure F3 in the "Site U1362" chapter and is available as a digital supplement (see COMPLTN in "Supplementary material"). PTFE = polytetrafluoroethylene.

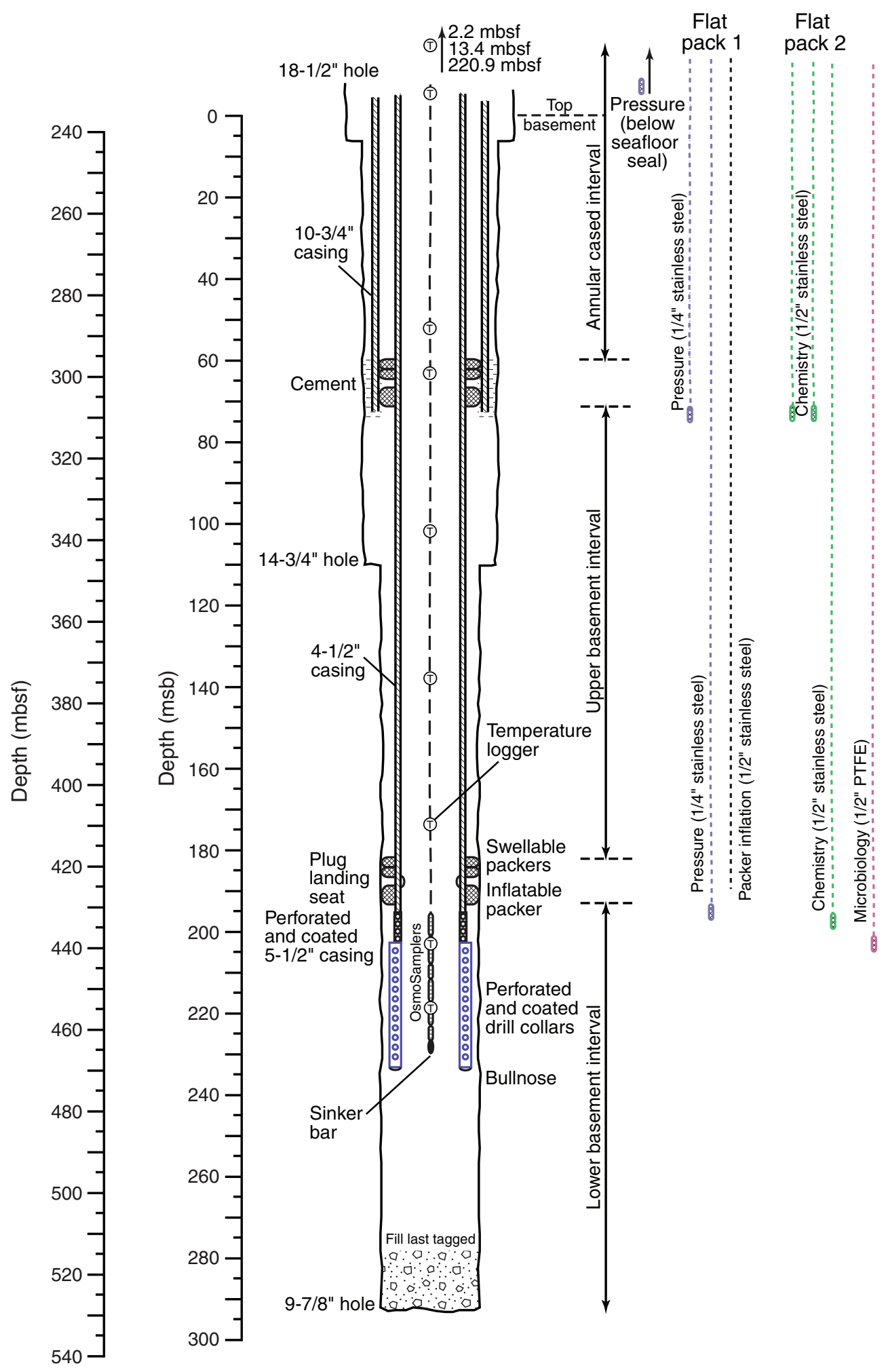


Figure F14. Photographs of Hole U1362A CORK wellhead immediately prior to deployment. CORK was briefly lowered below waterline to de-air pressure monitoring lines and was then raised so that valves could be set in final positions for deployment. A. Pressure monitoring bay. Pressure is monitored at two depths in basement with two lower valves (monitoring upon deployment), which can be switched to monitor seafloor pressure to evaluate instrument drift during periodic servicing visits with a submersible or ROV. Upper valve, which is used to monitor seafloor pressure upon deployment, can be switched to monitor cased interval between 16 and 103/4 inch casing during periodic servicing visits. B. Geochemistry sampling bay. All valves are deployed closed, and OsmoSampler systems will be attached during summer 2011 servicing. C. Flowmeter and microbiology sampling bay. Large ball valve is closed on deployment, with dust cover installed. flowmeter could be installed during summer 2011 servicing, although current plan is to use Hole U1362B for long-term flow experiment. Two microbiology sampling valves are connected to a single PTFE line that extends from the lowermost basement interval.
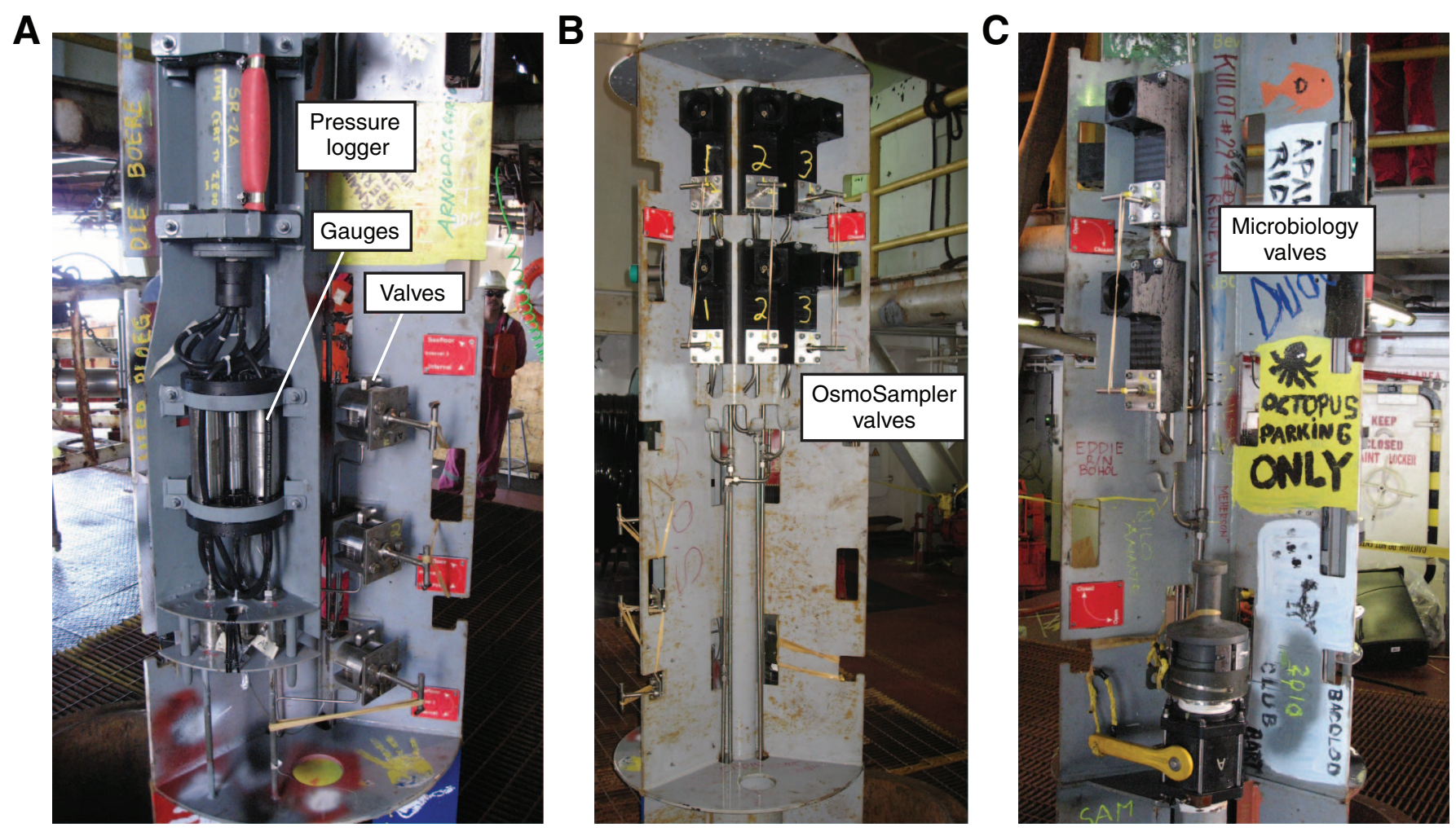
Figure F15. Diagram illustrating layout and distribution of instruments in Hole U1362B CORK. Drawing is to scale vertically but not horizontally, with correct shift between depth below seafloor and depth below top of basement. Hole completion information is summarized in Table T1, and instrumentation and monitoring and sampling depths are listed in Tables T2, T3, T4, and T5. Hole U1362B CORK accesses a single monitoring interval in basement, but also includes continuous monitoring of the annulus between 16 inch and 103/4 inch casing. Engineering drawing of Hole U1362B CORK is shown in Figure F4 in the "Site U1362" chapter and is available as a digital supplement (see COMPLTN in "Supplementary material"). PTFE = polytetrafluoroethylene.

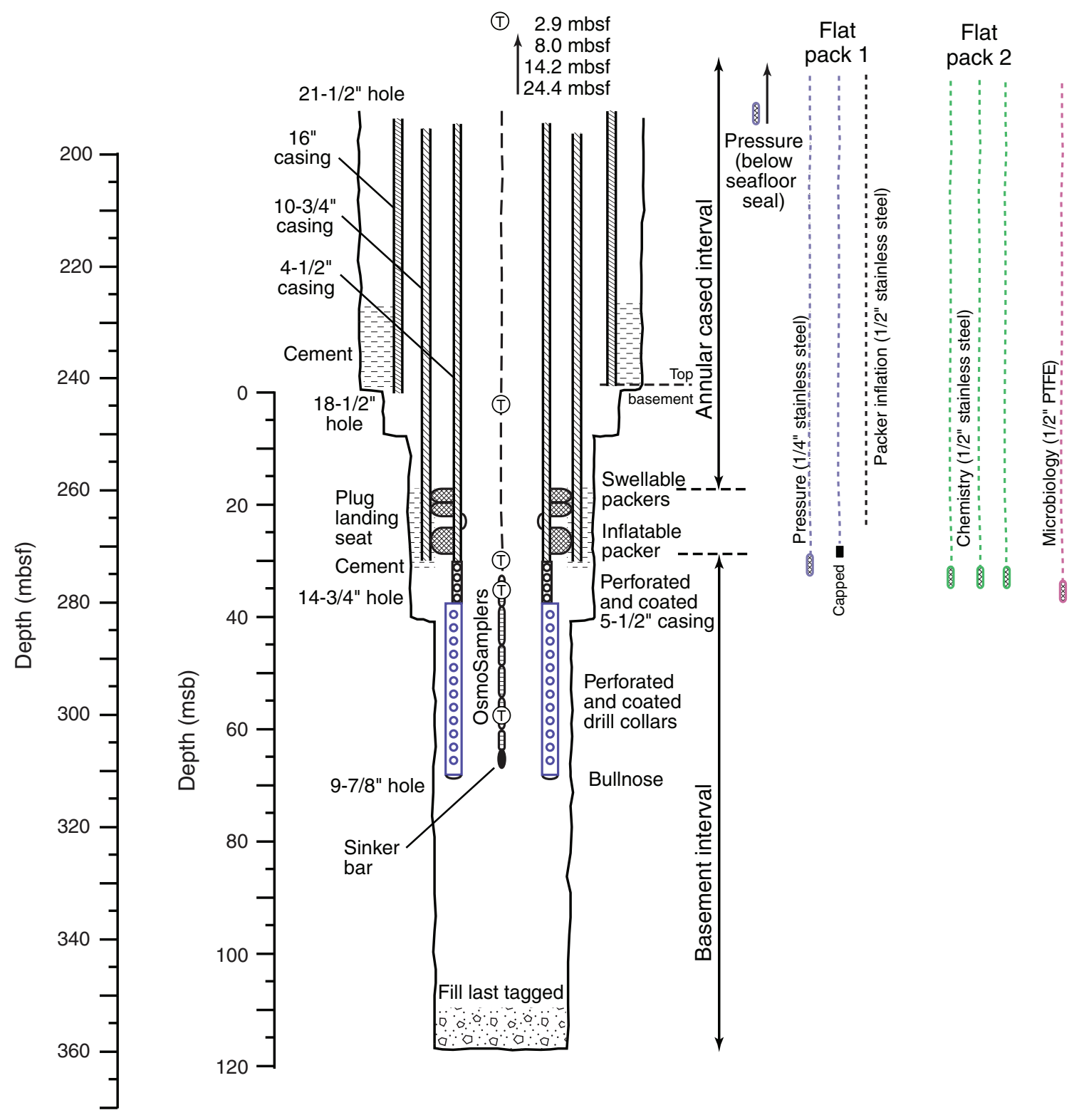


Figure F16. Photographs of Hole U1362B CORK wellhead immediately prior to deployment. CORK was briefly lowered below the waterline to de-air pressure monitoring lines and was then raised so that valves could be set in final positions for deployment. A. Pressure monitoring bay. Pressure is monitored at one depth in basement with lower valve, which can be switched to monitor seafloor pressure to evaluate instrument drift during periodic servicing visits with a submersible or ROV. Second valve is set for long-term monitoring of cased interval between 16 and 103/4 inch casing. Seafloor pressure is monitored using dedicated gauge. B. Geochemistry sampling bay. All valves are deployed closed, and OsmoSampler systems will be attached during summer 2011 servicing. C. Flowmeter and microbiology sampling bay. Large ball valve is closed on deployment with dust cover installed. flowmeter could be installed during summer 2011 servicing, although current plan is to use Hole U1362B for long-term flow experiment. Two microbiology sampling valves are connected to a single PTFE line that extends from the lowermost basement interval.
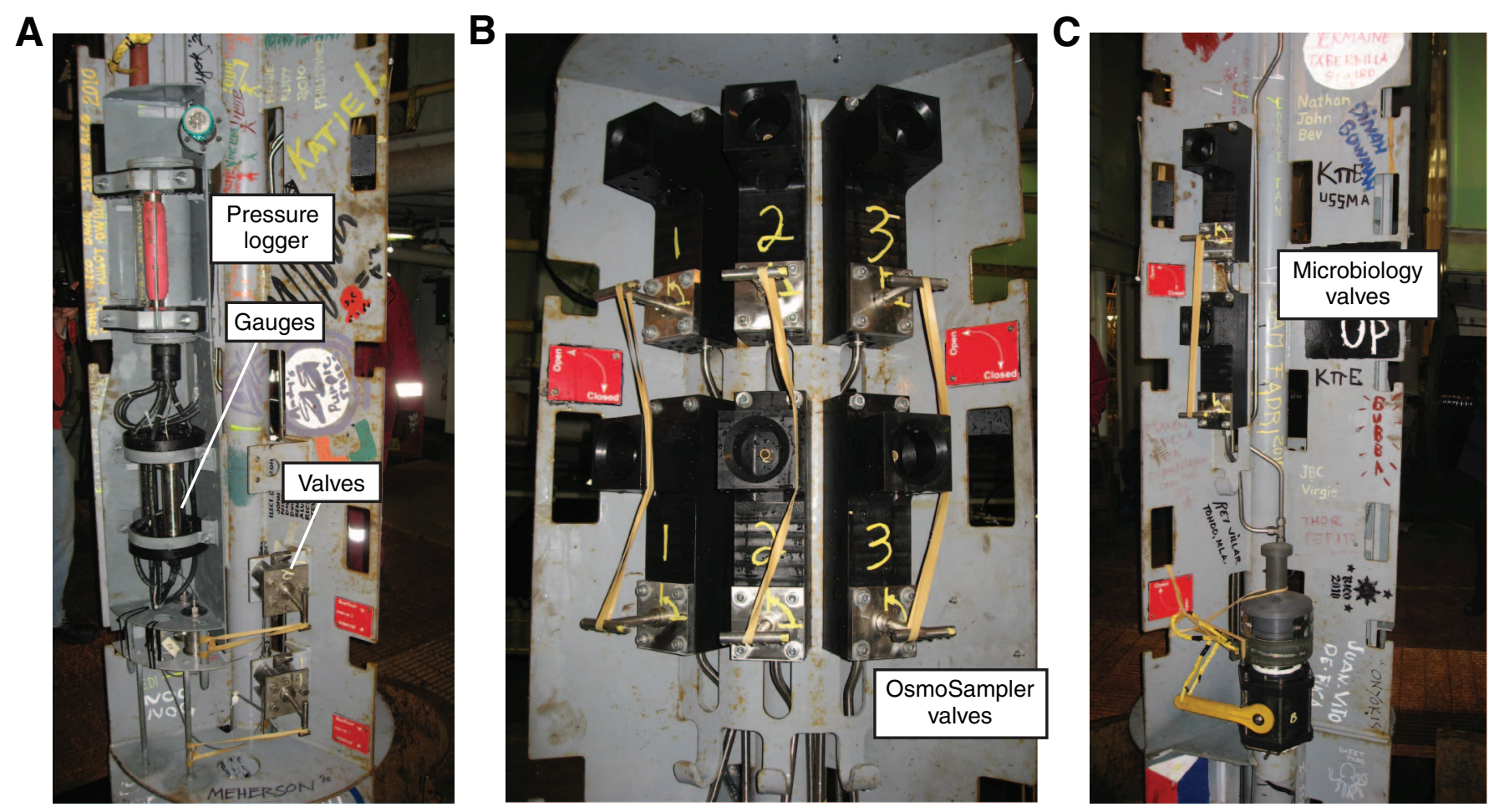
Figure F17. Photographs of CORK wellhead in Hole U1301A taken during R/V Atlantis Expedition AT15-66, prior to Expedition 327. All images were taken with ROV Jason. A. Overview of CORK wellhead. Note cement piled up around wellhead and "pits" formed as unset cement drained away through holes in landing platform and into underlying reentry cone. B. View of pressure monitoring bay at end of servicing operations. C. Arrangement of wellhead OsmoSamplers in geochemical sampling bay. D. Final OsmoSampler valve configuration. E. Final valve configuration of geomicrobiology sampling sled adjacent to microbiology sampling bay, with sample tubing attached to lowest of two valves. F. Weight stack placed on top of wellhead (having been moved from top of CORK in Hole U1301B).

A

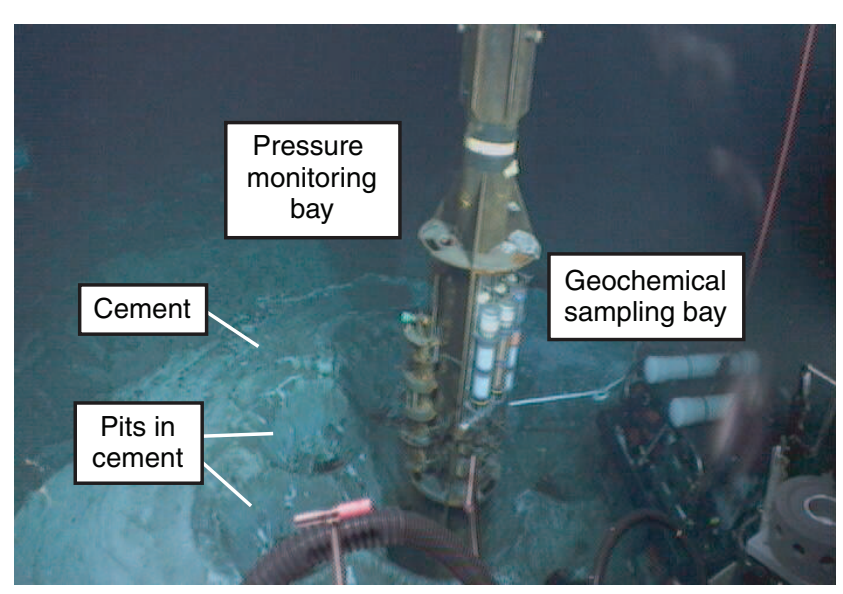

C

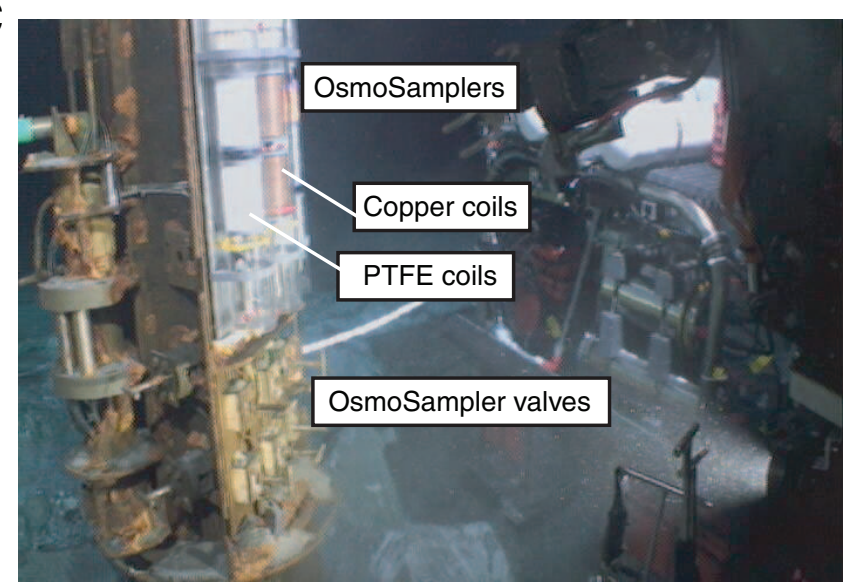

E

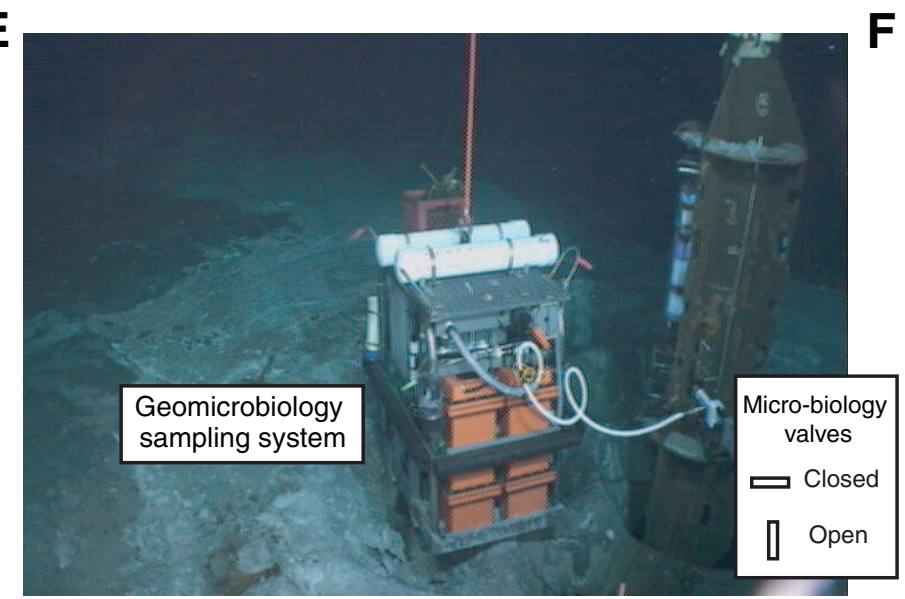

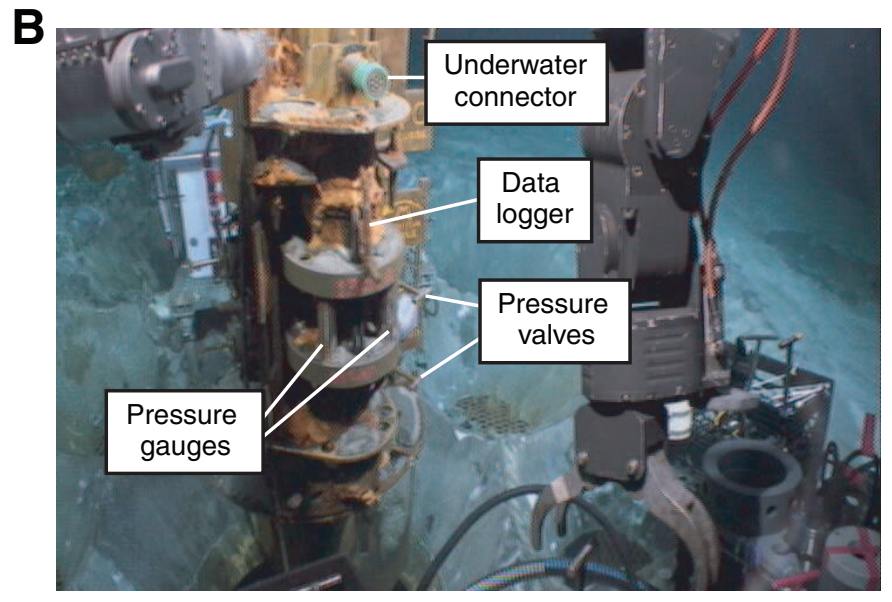

D

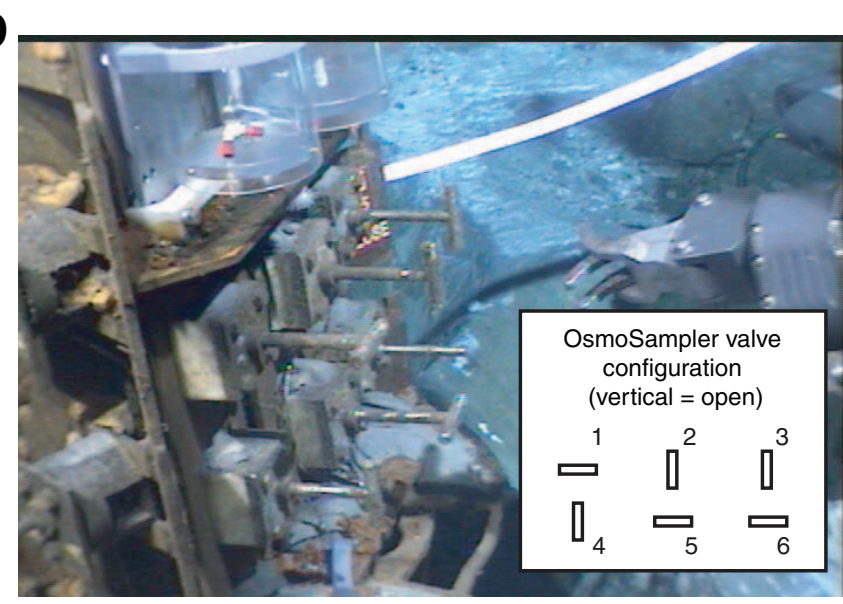

$\mathbf{F}$

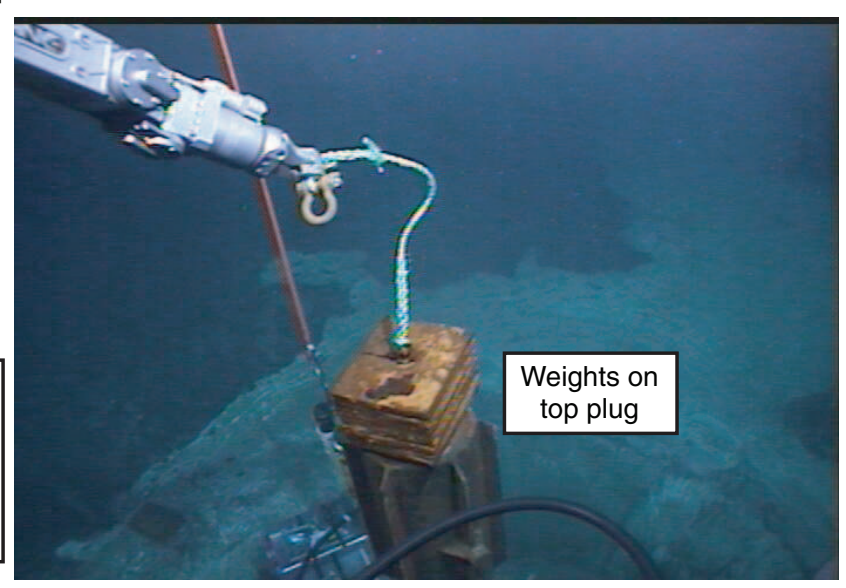


Figure F18. Photographs of CORK wellhead in Hole U1301B taken during R/V Atlantis Expedition AT15-66, prior to Expedition 327. All images were taken with ROV Jason. A. Overview of CORK wellhead. Wellhead sits relatively high above landing platform because it was extended prior to deployment during Expedition 301 (Fisher et al., 2005). Excess cement is also visible around wellhead and was observed to be set in cone just below landing platform. B. View of pressure monitoring bay at end of servicing operations. C. Arrangement of wellhead OsmoSamplers in geochemical sampling bay. D. Final OsmoSampler valve configuration. E. Final valve configuration of valves in microbiology sampling bay.

A

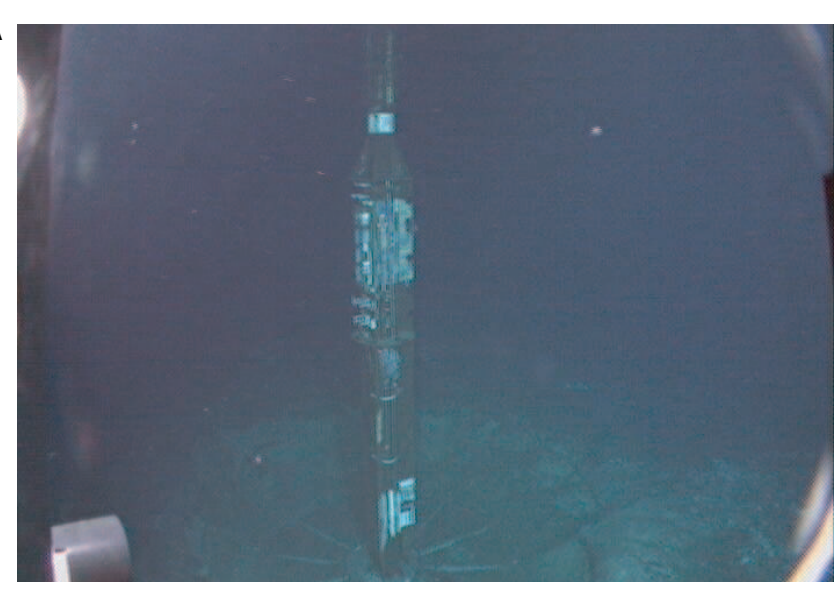

C

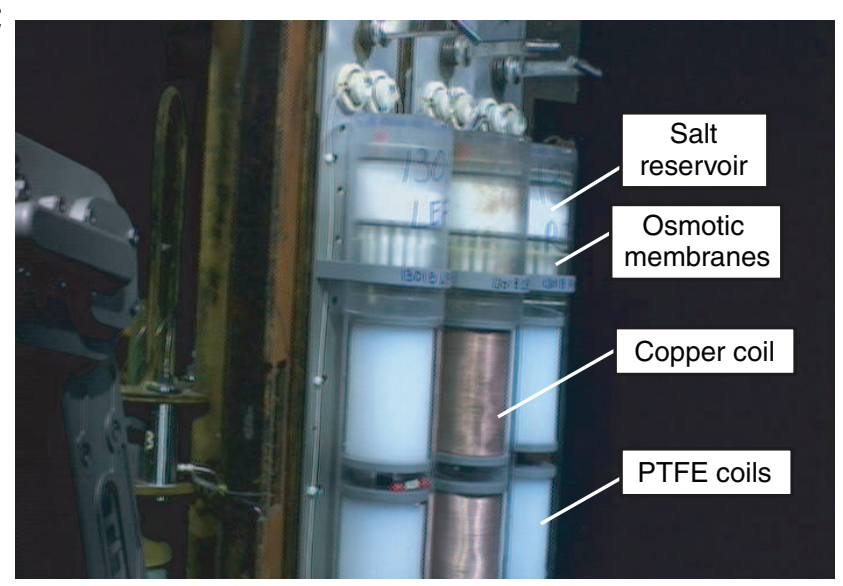

E

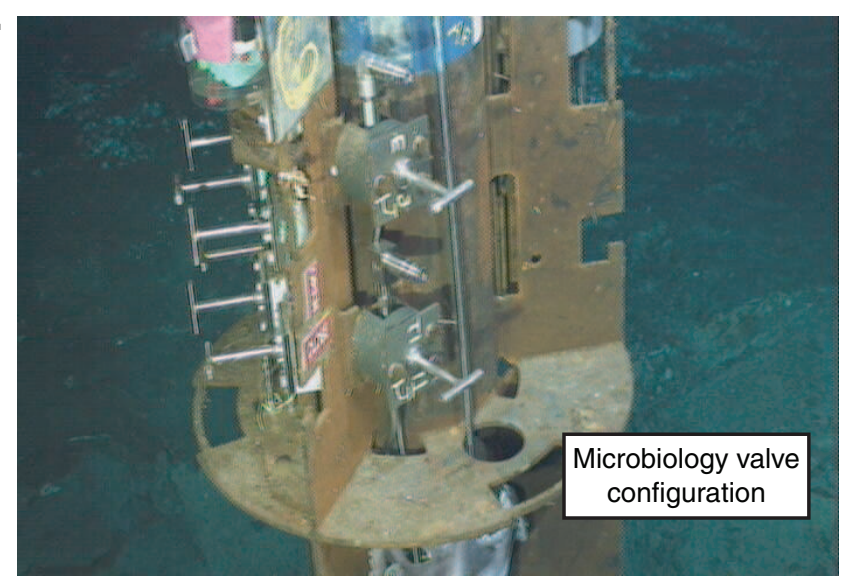

B

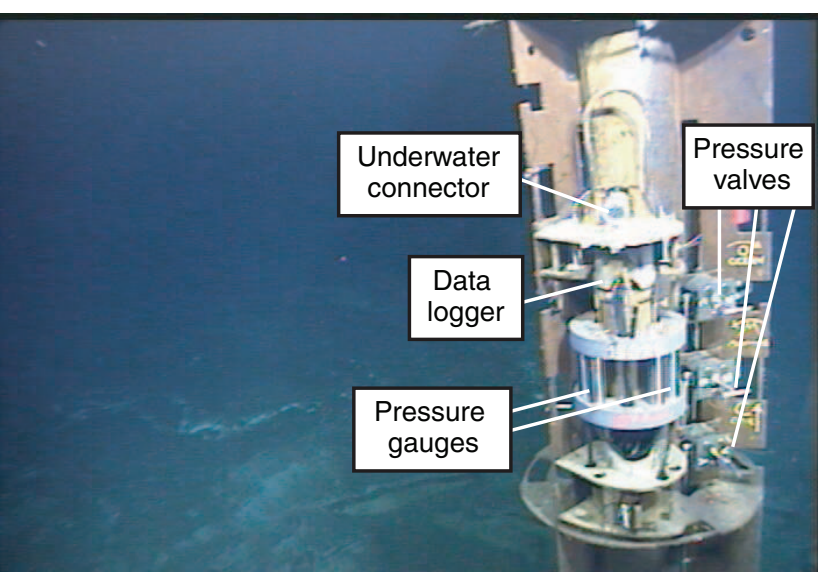

D

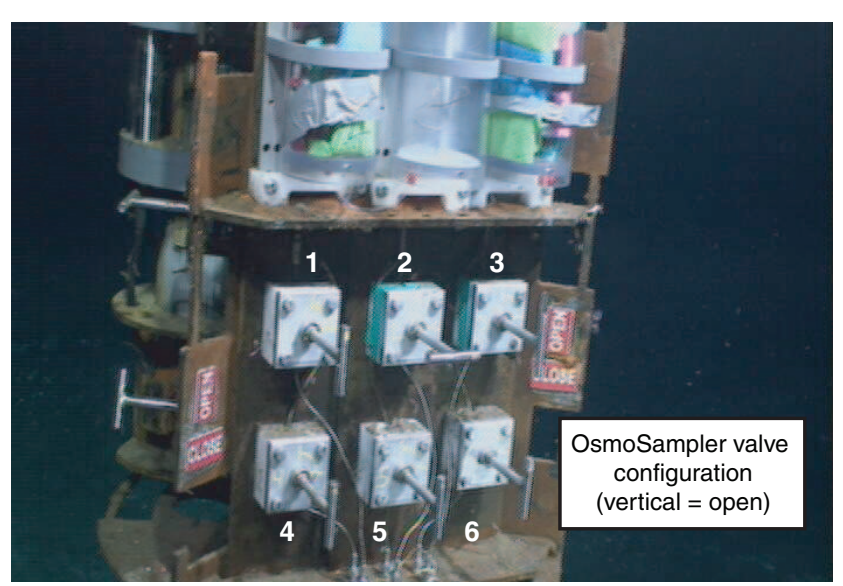


Figure F19. Photographs of CORK wellhead in Hole 1026B taken during R/V Atlantis Expedition AT15-66, prior to Expedition 327. All images were taken with ROV Jason. A. Overview of CORK wellhead, with two NEPTUNE Canada cables: temperature (top) and pressure (bottom). B. Detail view of cable connector at top of wellhead and Hole 1026B CORK mascot. $\mathrm{T}=$ temperature. C. View of pressure logger at end of servicing operations. $\mathrm{P}=$ pressure. D. View of pressure bay valves at end of servicing operations. E. Arrangement of wellhead OsmoSamplers in geochemical sampling bay. F. Final OsmoSampler valve configuration in geochemical sampling bay.

A

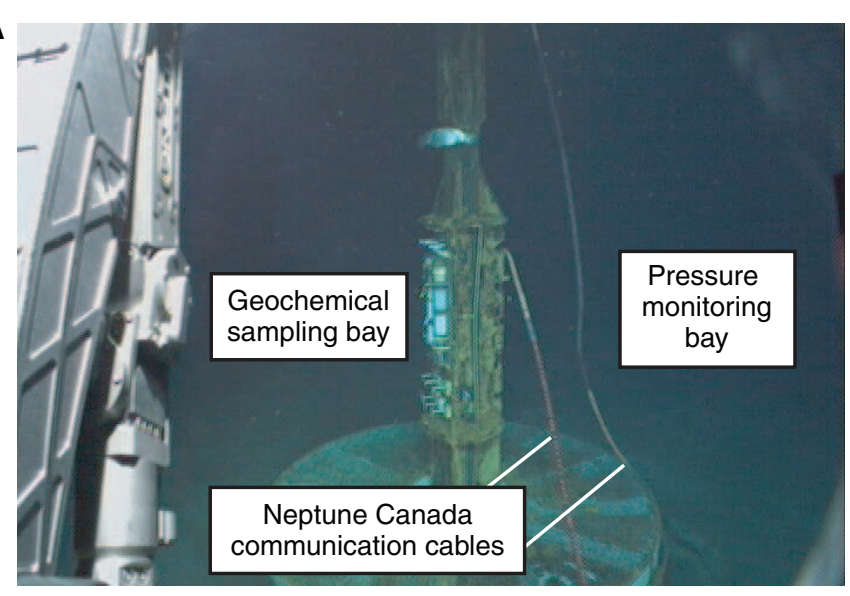

B

C

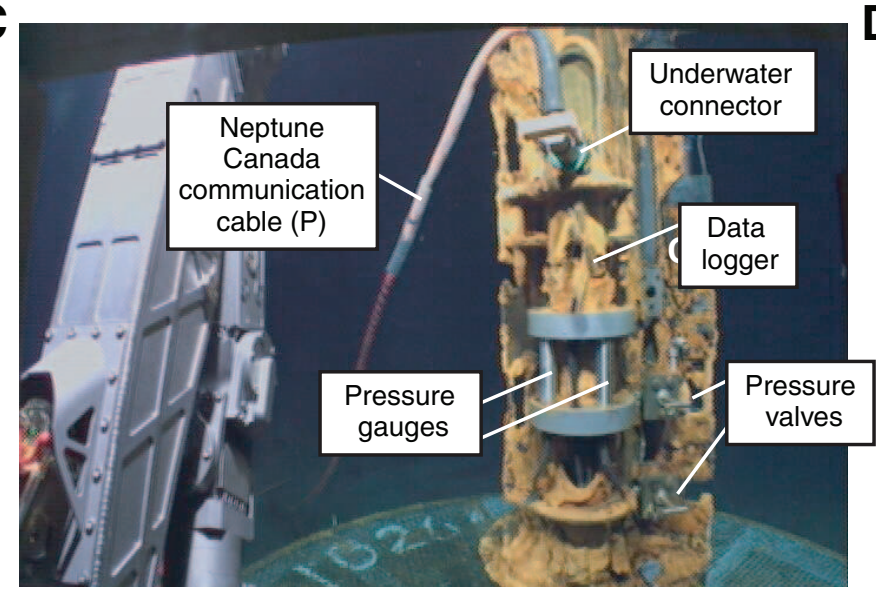

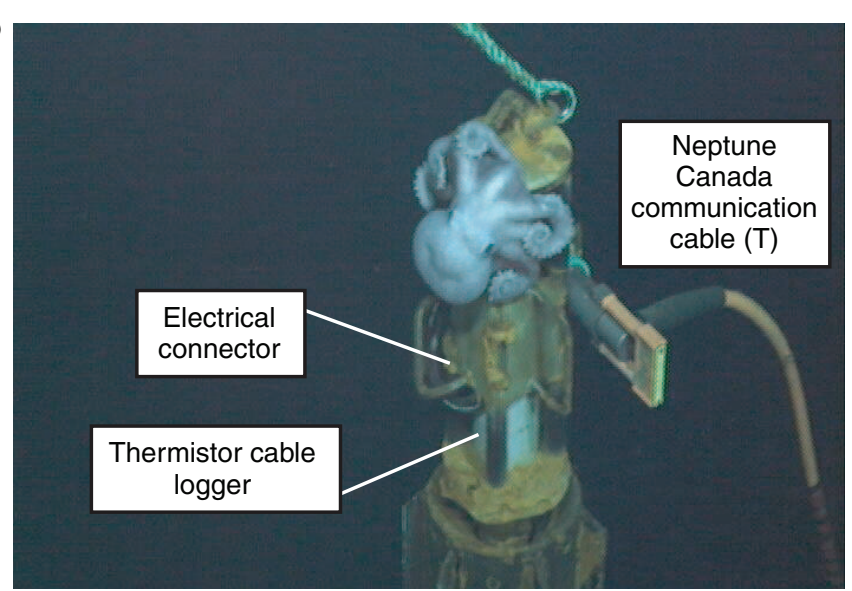

D

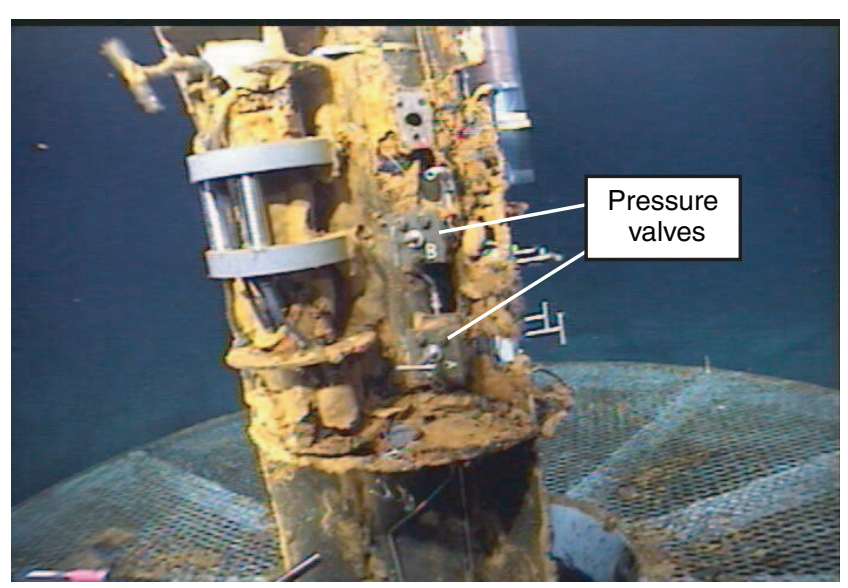

E

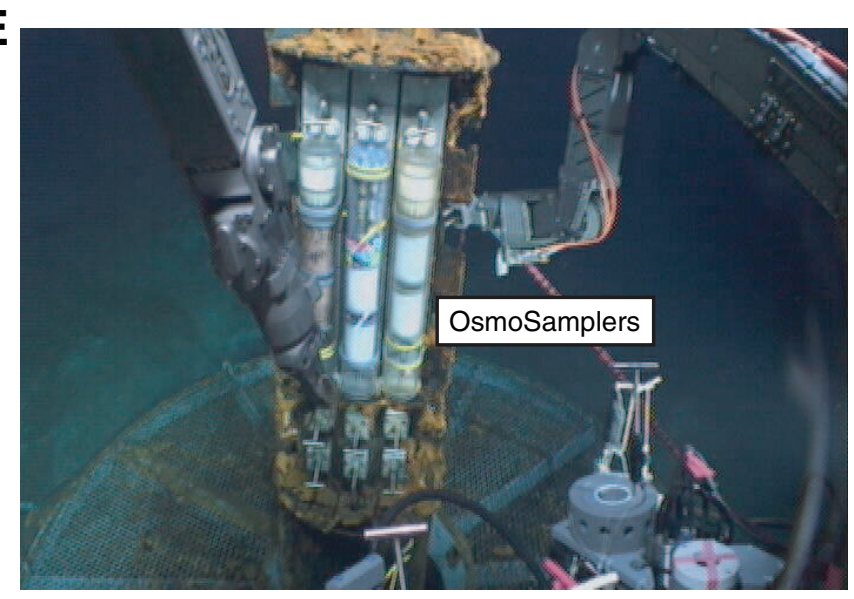

F

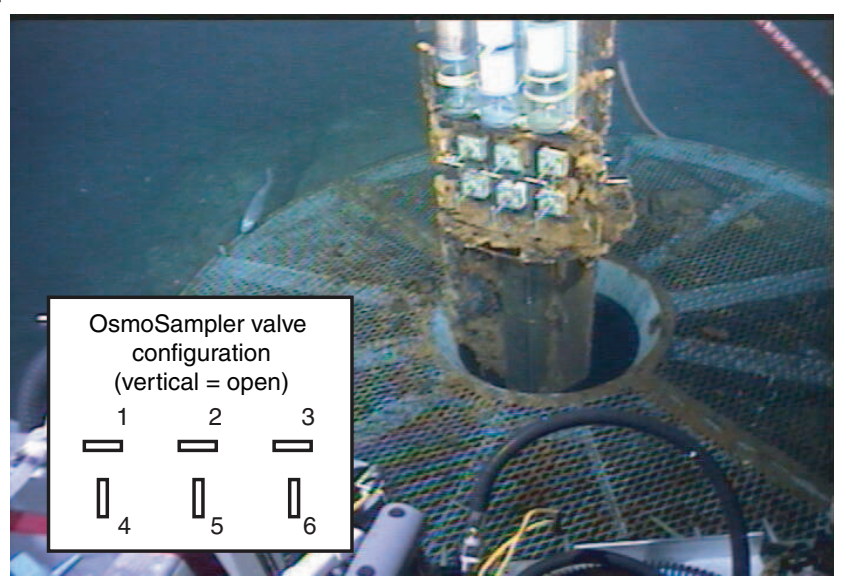


Table T1. Depths and geometrical parameters for holes, casing, and subseafloor borehole observatories (CORKs) associated with Expedition 327 and related experiments. (See table notes.)

\begin{tabular}{|c|c|c|c|c|c|c|c|}
\hline Component & Depth & $\begin{array}{c}\text { Hole } \\
\text { 1026B }\end{array}$ & $\begin{array}{c}\text { Hole } \\
1027 \mathrm{C}\end{array}$ & $\begin{array}{l}\text { Hole } \\
\text { U1301A }\end{array}$ & $\begin{array}{l}\text { Hole } \\
\text { U1301B }\end{array}$ & $\begin{array}{c}\text { Hole } \\
\text { U1362A }\end{array}$ & $\begin{array}{l}\text { Hole } \\
\text { U1362B }\end{array}$ \\
\hline Seafloor & mbrf & 2669.1 & 2667.3 & 2667.3 & 2667.8 & 2672.0 & 2672.0 \\
\hline Basement & mbsf & 247.1 & $613.7^{*}$ & 262.2 & 265.2 & 236.0 & 242.0 \\
\hline \multirow{2}{*}{ Total depth of hole* } & mbsf & 295.2 & 632.7 & 369.7 & 582.8 & 528.0 & 359.0 \\
\hline & msb & 48.1 & 19.0 & 107.5 & 317.6 & 292.0 & 117.0 \\
\hline \multirow[t]{2}{*}{20 or $21-1 / 2$ inch hole } & mbsf & $N A^{\dagger}$ & $N A^{\dagger}$ & 270.2 & 268.2 & 236.0 & 243.5 \\
\hline & $\mathrm{msb}$ & NA & NA & 8.0 & 3.0 & 0.0 & 1.5 \\
\hline \multirow[t]{2}{*}{ 18-1/2 inch hole } & mbsf & $N A^{\dagger}$ & $N A^{\dagger}$ & 271.9 & 276.2 & 242.0 & 250.0 \\
\hline & msb & NA & NA & 9.7 & 11.0 & 6.0 & 8.0 \\
\hline \multirow[t]{2}{*}{ 14-3/4 inch hole } & mbsf & 350.2 & 584.8 & 369.7 & 350.2 & 346.0 & 282.0 \\
\hline & msb & 103.1 & -28.9 & 107.5 & 85.0 & 110.0 & 40.0 \\
\hline \multirow[t]{2}{*}{$9-7 / 8$ inch hole } & mbsf & 295.2 & 632.7 & NA & 582.8 & 528.0 & 359.0 \\
\hline & msb & 48.1 & 19.0 & NA & 317.6 & 292.0 & 117.0 \\
\hline 20 inch casing shoe & mbsf & $\mathrm{NA}^{\dagger}$ & $N A^{\dagger}$ & 42.9 & 42.5 & 53.0 & 53.0 \\
\hline 16 inch casing shoe & mbsf & 39.7 & 37.6 & 265.3 & 270.9 & 230.0 & 242.0 \\
\hline \multirow[t]{2}{*}{$10-3 / 4$ inch casing shoe } & mbsf & 248.5 & 578.7 & 277.1 & 346.1 & 308.5 & 272.0 \\
\hline & msb & 1.4 & -35.0 & 14.9 & 80.9 & 72.5 & 30.0 \\
\hline \multirow[t]{2}{*}{ Base of CORK system } & mbsf & 201.6 & NA & 291.9 & 291.9 & 469.7 & 311.0 \\
\hline & msb & -45.5 & NA & 29.7 & 26.8 & 233.7 & 69.0 \\
\hline \multirow[t]{2}{*}{ Packer depth(s) } & mbsf & 198.1 & NA & 270.3 & $428.8,472.2$ & $307.3,429.2$ & 271.1 \\
\hline & msb & -49.0 & NA & 8.1 & $163.6,207.0$ & $71.3,193.2$ & 29.1 \\
\hline
\end{tabular}

Notes: $\mathrm{mbrf}=$ meters below rig floor, $\mathrm{mbsf}=$ meters below seafloor, $\mathrm{msb}=$ meters subbasement (msb values $<0$ indicate location within the sedimentary section). ${ }^{*}=$ basement depth in Hole $1027 \mathrm{C}$ refers to uppermost ocean crust below a sill and intercalated sediments. $\dagger=$ conductor casing jetted in for Holes 1026B and 1027C had 16 inch outer diameter and no larger hole was drilled. Packer depths reported are for base of deepest packer element in each set deployed. $\mathrm{NA}=$ not applicable.

Table T2. Specifications of pressure measurement and logging systems in CORKs related to Expedition 327 and associated experiments, as of the end of Expedition 327. (See table notes.)

\begin{tabular}{|c|c|c|c|c|c|c|}
\hline Component & Hole 1026B & Hole $1027 \mathrm{C}$ & Hole U1301A & Hole U1301B & Hole U1362A & Hole U1362B \\
\hline CORK deployed & $\begin{array}{l}\text { Expedition } 301 \\
\quad(2004)\end{array}$ & Leg 168 (1996) & $\begin{array}{l}\text { Expedition } 301 \\
\quad(2004)\end{array}$ & $\begin{array}{l}\text { Expedition } 301 \\
\quad(2004)\end{array}$ & $\begin{array}{l}\text { Expedition } 327 \\
\quad(2010)\end{array}$ & $\begin{array}{l}\text { Expedition } 327 \\
\quad(2010)\end{array}$ \\
\hline Logger deployed & Alvin (2007) & Alvin (1999) & Alvin (2007) & Alvin (2007) & $\begin{array}{l}\text { Expedition } 327 \\
(2010)\end{array}$ & $\begin{array}{l}\text { Expedition } 327 \\
(2010)\end{array}$ \\
\hline Pressure channels & 2 & 2 & 3 & 4 & 3 & 3 \\
\hline Dedicated seafloor gauge & Yes & Yes & Yes & Yes & Yes & Yes \\
\hline Basement intervals & 1 & 1 & 1 & 3 & 2 & 1 \\
\hline Gauge serial numbers & 107549,107550 & 62719,62718 & $\begin{array}{l}106844,106855 \\
106856\end{array}$ & $\begin{array}{l}107551,107553 \\
107554,107560\end{array}$ & $\begin{array}{l}75738,75739 \\
89098\end{array}$ & $\begin{array}{l}94000,94223 \\
93076\end{array}$ \\
\hline Isolated cased interval & No & No & $\mathrm{No}^{*}$ & $\mathrm{No}^{*}$ & Yes (spot) $)^{\dagger}$ & Yes \\
\hline Sample rate $(s)$ & $1 \mathrm{~s}$ & 3600 & 60 & 60 & 60 & 60 \\
\hline Memory (Mb) & 256 & 256 & 256 & 256 & 256 & 256 \\
\hline
\end{tabular}

Notes: ${ }^{*}=$ upper basement interval includes gap between $10^{3 / 4}$ and 16 inch casing strings that is not sealed at the base. $\dagger=$ gauge currently being used for seafloor monitoring can be switched with wellhead valve to spot-check annular gap between $10^{3 / 4}$ and 16 inch casing. Original Hole 1026B and 1027C CORKs were deployed during ODP Leg 168; Hole 1026B CORK was replaced during IODP Expedition 301. Logger deployments are most recent as of end of Expedition 327. Pressure gauges are identified by serial number from bottom to top, with seafloor at top where applicable. The old data logger in Hole 1027C CORK is not thought to be operating at present; a new logger is planned for deployment in summer 2011. 
Table T3. Depths, types, and serial numbers of temperature loggers and related string parameters deployed in Expedition 301 and 327 CORKs as of end of Expedition 327. (See table notes.)

\begin{tabular}{lrrr}
\hline \multirow{2}{*}{ Manufacturer } & \multicolumn{3}{c}{ Depth } \\
\cline { 2 - 4 } (serial number) & msd & mbsf & \multicolumn{1}{c}{ msb } \\
\hline Hole U1362A & & & \\
Onset (768608) & 8.4 & 2.2 & -233.8 \\
Onset (768609) & 19.7 & 13.4 & -222.6 \\
Antares (1857021) & 227.2 & 220.9 & -15.1 \\
Antares (1857022) & 237.4 & 231.2 & -4.8 \\
Antares (1857023) & 294.9 & 288.6 & 52.6 \\
Antares (1857024) & 305.1 & 298.8 & 62.8 \\
Antares (1857027) & 344.1 & 337.9 & 101.9 \\
Antares (1857028) & 380 & 373.8 & 137.8 \\
Antares (1857031) & 415.9 & 409.7 & 173.7 \\
End of Spectra cable & 438.8 & 432.6 & 196.6 \\
Antares (1857025) & $\mathrm{NA}$ & 438.6 & 202.6 \\
Antares (1857026) & $\mathrm{NA}$ & 454.1 & 218.1 \\
End of sinker bar & $\mathrm{NA}$ & 469.7 & 233.7 \\
Hole U1362B & & & \\
Antares (1857034) & 9.0 & 2.9 & -239.1 \\
Antares (1857038) & 14.0 & 8.0 & -234.0 \\
Antares (1857039) & 20.0 & 14.2 & -227.8 \\
Antares (1857040) & 30.0 & 24.4 & -217.6 \\
Onset (768607) & 246.3 & 245.0 & 3.0 \\
Onset (768610) & 273.8 & 273.0 & 31.0 \\
End of Spectra cable & 282.6 & 276.3 & 34.3 \\
Antares (1857035) & $\mathrm{NA}$ & 276.9 & 34.9 \\
Antares (1857037) & $\mathrm{NA}$ & 301.4 & 59.4 \\
End of sinker bar & $\mathrm{NA}$ & 310.0 & 68.0 \\
Hole U1301A & & & \\
Onset (768616) & 8.0 & 2.3 & -259.9 \\
Antares (1857030) & 16.0 & 10.3 & -251.9 \\
Onset (768604) & 255.4 & 249.7 & -12.5 \\
Onset (768598) & 265.4 & 259.7 & -2.5 \\
Antares (1857004) & 270.4 & 264.7 & 2.5 \\
End of Spectra cable & 275.3 & $\mathrm{NA}$ & $\mathrm{NA}$ \\
Onset (768596) & $\mathrm{NA}$ & 274.5 & 12.3 \\
Antares (1857036) & $\mathrm{NA}$ & 283.6 & 21.4 \\
Onset (768603) & $\mathrm{NA}$ & 284.5 & 22.3 \\
End of sinker bar & $\mathrm{NA}$ & 290.7 & 28.5 \\
Hole U1301B & & & \\
Antares (1857029) & 10.2 & 2.8 & -262.4 \\
Antares (1857032) & 20.4 & 13.0 & -252.2 \\
Antares (1857033) & 30.6 & 23.2 & -242.0 \\
End of Spectra cable & 51.0 & 43.6 & -221.6 \\
End of sinker bar & 54.7 & 47.3 & -217.9 \\
\hline & & & \\
\hline
\end{tabular}

Notes: $\mathrm{msd}=$ meters Spectra depth, $\mathrm{mbsf}=$ meters below seafloor, $\mathrm{msb}=$ meters subbasement $(\mathrm{msb}$ values $<0$ indicate deployment within the sedimentary section). Depths for Holes U1362A, U1362B, and U1301B are corrected for Spectra cable stretch of 2\%. Depths for Hole U1301A are not corrected for stretch because cable has plug in landing seat at bottom and cable should be relatively slack. A thermistor cable is recording borehole temperatures at 16 depths in Hole 1026B, with data accessible through the NEPTUNE Canada website (www.neptunecanada.ca/). End of Spectra cable is length/depth. OsmoSampler systems and a sinker bar are suspended below this cable in Holes U1362A and U1362B, and a sinker bar is suspended in Hole U1301B. In Hole U1301A, the Spectra cable terminates in top of bottom plug, with some slack included to assure that the plug landed. Tools listed after end of Spectra cable were deployed in PVC holders mounted inside OsmoSampler systems, below depth extent of Spectra cable. Hole U1301A instrument string was deployed with submersible Alvin in summer 2009. All others were deployed during Expedition 327. NA = not applicable. 
Table T4. Specifications of OsmoSampler deployed in Expedition 301 and 327 CORKs as of end of Expedition 327. (See table notes.)

\begin{tabular}{|c|c|c|c|}
\hline \multirow[b]{2}{*}{ Component } & \multirow{2}{*}{$\begin{array}{l}\text { Length } \\
(\mathrm{m})\end{array}$} & \multicolumn{2}{|c|}{ Depth } \\
\hline & & $\mathrm{mbsf}$ & $\mathrm{msb}$ \\
\hline \multicolumn{4}{|l|}{ Hole U1362A } \\
\hline Acid addition & 5.4 & 438.0 & 202.0 \\
\hline MBIO (Antares 1857025)* & 6.7 & 444.8 & 208.8 \\
\hline Standard & 3.4 & 448.2 & 212.2 \\
\hline Enrichment & 5.4 & 453.6 & 217.6 \\
\hline BOSS (Antares 1857026)* & 5.4 & 459.1 & 223.1 \\
\hline Gas tight (copper) & 3.4 & 462.5 & 226.5 \\
\hline Sinker bar $(200 \mathrm{lb})$ & 3.7 & 466.2 & 230.2 \\
\hline Total length: & 33.6 & & \\
\hline Bullnose depth & & 469.7 & 233.7 \\
\hline \multicolumn{4}{|l|}{ Hole U1362B } \\
\hline Standard (Antares 1857035)* & 3.4 & 279.9 & 37.9 \\
\hline MBIO & 6.7 & 286.6 & 44.6 \\
\hline Acid addition & 5.4 & 292.0 & 50.0 \\
\hline Enrichment & 5.4 & 297.5 & 55.5 \\
\hline Gas tight (copper) & 3.4 & 300.9 & 58.9 \\
\hline BOSS (Antares 1857037)* & 5.4 & 306.4 & 64.4 \\
\hline Sinker bar $(200 \mathrm{lb})$ & 3.7 & 310.0 & 68.0 \\
\hline Total length: & 33.6 & & \\
\hline Bullnose depth & & 311.5 & 69.5 \\
\hline \multicolumn{4}{|l|}{ Hole 1026B } \\
\hline Gas tight (copper) & 2.8 & 200.6 & -46.5 \\
\hline Standard & 2.8 & 203.5 & -43.6 \\
\hline MBIO & 2.8 & 206.3 & -40.8 \\
\hline MBIO & 2.8 & 209.2 & -37.9 \\
\hline Standard & 2.8 & 212.0 & -35.1 \\
\hline Sinker bar (50 lb) & 1.0 & 213.0 & -34.1 \\
\hline Total length: & 15.2 & & \\
\hline \multicolumn{4}{|l|}{ Hole U1301A } \\
\hline Gas tight (copper) (Onset 768596) & 3.4 & 276.9 & 14.7 \\
\hline MBIO (Antares 1857036) & 6.7 & 283.6 & 21.4 \\
\hline Acid addition (Onset 768603) & 5.4 & 288.9 & 26.7 \\
\hline Sinker bar (100 lb) & 1.8 & 290.7 & 28.5 \\
\hline Total length: & 17.2 & & \\
\hline Bullnose depth & & 292.0 & 29.8 \\
\hline
\end{tabular}

Notes: ${ }^{*}=$ temperature logger mounted in PVC holder inside OsmoSampler assembly. System components are listed top to bottom for each hole. Instruments in Holes U1362A and U1362B were deployed during Expedition 327. Instruments in Hole 1026B were deployed with Alvin in summer 2008. Instruments in Hole U1301A were deployed with Alvin in summer 2009. Depths reported are for base of each component: mbsf $=$ meters below seafloor, msb = meters subbasement. Total length is from top of OsmoSampler string to base of sinker bar. Depth of bullnose tip is at end of CORK casing. All Expedition 327 OsmoSampler systems were deployed above this depth inside perforated and coated casing and collars. 
Table T5. Monitoring and sampling points in Expedition 327 CORKs. (See table notes.)

\begin{tabular}{|c|c|c|c|c|c|}
\hline \multirow{2}{*}{$\begin{array}{l}\text { Monitoring/Sampling } \\
\text { purpose }\end{array}$} & \multirow[b]{2}{*}{ Valve ID } & \multirow{2}{*}{$\begin{array}{l}\text { Screen } \\
\text { material }\end{array}$} & \multicolumn{2}{|c|}{ Depth } & \multirow[b]{2}{*}{ Comments } \\
\hline & & & mbsf & msb & \\
\hline \multicolumn{6}{|l|}{ Hole U1362A } \\
\hline Pressure & 1 & Stainless steel & $430.1,-3.66$ & 194.1 & Deep basement interval \\
\hline Pressure & 2 & Stainless steel & $307.8,-3.96$ & 71.8 & Shallow basement interval \\
\hline Pressure & 3 & None & $0.1,-4.26$ & NA & Cased interval \\
\hline Geochemistry & $1,1^{\prime}$ & Stainless steel & 434.2 & 198.2 & Deep basement interval, $\sim 5 \mathrm{~m}$ below base of lower packer \\
\hline Geochemistry & $2,2^{\prime}$ & Stainless steel & 309.3 & 73.3 & Shallow basement interval, $\sim 2 \mathrm{~m}$ below base of lower packer \\
\hline Geochemistry & $3,3^{\prime}$ & Stainless steel & 309.3 & 73.3 & Shallow basement interval, $\sim 2 \mathrm{~m}$ below base of lower packer \\
\hline Microbiology & 1,2 & Titanium & 439.8 & 203.8 & Deep basement interval, $~ 10.6 \mathrm{~m}$ below base of lower packer \\
\hline \multicolumn{6}{|l|}{ Hole U1362B } \\
\hline Pressure & 1 & Stainless steel & $272.0,-3.66$ & 30.0 & Basement interval \\
\hline Pressure & 2 & None & $0.1,-3.96$ & NA & Cased interval \\
\hline Pressure & 3 & None & -4.3 & NA & Dedicated seafloor \\
\hline Geochemistry & $1,1^{\prime}$ & Stainless steel & 278.8 & 36.8 & Basement interval, $\sim 8 \mathrm{~m}$ below base of packer, center of $5-1 / 2$ inch casing \\
\hline Geochemistry & $2,2^{\prime}$ & Stainless steel & 278.8 & 36.8 & Basement interval, $\sim 8 \mathrm{~m}$ below base of packer, center of $5-1 / 2$ inch casing \\
\hline Geochemistry & $3,3^{\prime}$ & Stainless steel & 278.8 & 36.8 & Basement interval, $\sim 8 \mathrm{~m}$ below base of packer, center of $5-1 / 2$ inch casing \\
\hline Microbiology & 1,2 & Titanium & 281.7 & 39.7 & Basement interval, $\sim 10.6 \mathrm{~m}$ below base of lower packer \\
\hline
\end{tabular}

Notes: Valve ID indicates valve in CORK wellhead. The two microbiology valves in each wellhead are connected to a single sampling line. Geochemical values are also replicated, with two valves monitoring each depth interval. Tubing used for monitoring and sampling terminates in wire-wrapped miniscreens, except for pressure monitoring just below seafloor CORK seal (both CORKs) and dedicated seafloor gauge (Hole U1362B). Depths reported as meters below seafloor (mbsf) and meters subbasement (msb) refer to termination of sampling line. Second pressure values (negative in mbsf column) refer to seafloor monitoring points. $\mathrm{NA}=$ not applicable. 